\title{
System dynamics model of cervical cancer vaccination and screening interventions in Kenya
}

\author{
Lucy W Kivuti-Bitok ${ }^{1 *}$, Geoff McDonnell ${ }^{2}$, Roudsari Abdul ${ }^{3}$ and Ganesh P Pokhariyal ${ }^{4}$
}

\begin{abstract}
Objectives: This paper presents a simulation model for evaluating the possible effects of a screening and vaccination campaign against Human Papillomavirus [HPV] in Kenya.

Method: A System Dynamics model was developed using the iThink ${ }^{\mathrm{TM}}$ computer simulation package. The model was based on data extracted from epidemiological, demographic and published research and where data was not available, expert opinion was sought. The deterministic model stratified the population by vaccination status, screening status and HPV infection status. The model was simulated to estimate outputs for the next 50 years from 2011. Cost Utility indicators of Disability Adjusted Life Years (DALYs) and cost per averted DALY were used for economic evaluation.
\end{abstract}

Results: The model predicted that catch up vaccination had the greatest impact in reducing the prevalence of cervical cancer. This was followed by Primary vaccination, with early detection through Screening having the lowest impact of the three choices of interventions in respect of averted cases of cervical cancer and DALY estimates.

Conclusion: Kenya as a country should consider adoption of secondary /catch up vaccination as an immediate measure to curb cervical cancer followed by primary vaccination of pre-adolescent girls. Screening should be a complementary measure(s). This model provides a policy decision support vehicle that can allow for choice between different interventions based on their expected outcomes. It also allows modification to accommodate new research results and information to assess the clinical impact of different policies and interventions in cervical cancer management in Kenya.

Keywords: Dynamic, Simulation, Cervical, Cancer, Kenya

\section{Introduction}

\section{Burden of cervical cancer in Kenya}

Cervical cancer is estimated to account for $15 \%$ of all female cancers and cause approximately 46,000 deaths each year in women aged 15-49 in developing countries $[1,2]$. Cervical cancer continues to have a devastating effect on women's health in Kenya. It is the most frequent cancer among women in Kenya. It is also the second most frequent cancer among women between 15 and 44 years of age after breast cancer [3]. Specific disease indicators are summarized in Table 1.

A crude incidence rate of 16.5 per 100,000 population per year was reported in Kenya in 2009. Estimates indicate that every year 2600 women are diagnosed with cervical

\footnotetext{
* Correspondence: lukibitok@uonbi.ac.ke

${ }^{1}$ School of Nursing Sciences, University of Nairobi, P.O BOX

19676-KNH-00202, Nairobi, Kenya

Full list of author information is available at the end of the article
}

cancer in Kenya and 2100 die from the disease. It is projected that in 2025, there will be 4100 new cases of cervical cancer in Kenya and 3300 deaths as a result of cervical cancer. Some facilities in the capital city, Nairobi, have reported as high as $10-15$ new cases of cervical cancer each week [3].

\section{Strategies employed in management of cervical cancer in Kenya}

Different stakeholders have taken different measures to curb cervical cancer in Kenya. These interventions range from inclusion of cervical cancer in training curricula, prevention and promotion services such as screening, vaccination, male circumcision as well as health education. Treatment interventions have also been undertaken. For those with positive tests, provision of curative services which include Cryotherapy, loop electrosurgical excision 
Table 1 PARAMETER[S] estimates and sources

\begin{tabular}{|c|c|c|}
\hline Factor[s] & Value & $\begin{array}{l}\text { Source of } \\
\text { information }\end{array}$ \\
\hline
\end{tabular}

\section{Cervical cancer BASE CASE [Year 2010]}

Prevalence rate

Crude Incidence rate/100000

Number of deaths

Number of cases

No diagnosed with cervical cancer each year

2011 life expectancy in Kenya

Average age of onset of cervical cancer

Average duration of cervical cancer

\section{DALY assumptions for cancer}

Age of onset of death or disability in years [a]

Disability weight [D]

Percent of surviving cases with sequelae

Mortality to incidence ratio

Mortality from other causes not directly connected to Cancer of Cervix

Crude mortality rate

Age-standardized mortality rate

Screening coverage rate within 3 years

Rate of primary vaccination

Rate of secondary vaccination

No of primary vaccinations required to avert one case of Ca cervix

No of primary vaccinations required to avert one case of Ca cervix

No of secondary/catch up vaccinations required to avert one case of Ca cervix

\section{E-health usage}

Percentage with access to internet

Percentage with access to mobile phone

Percentage with positive attitude towards use of e-health

\section{PROGNOSIS OF undiagnosed Ca. cervix}

Percentage of death from invasive cancer

time span between infection of HPV and development

of carcinoma in Situ

Years taken by precancerous cells to progress to cancerous cells

Percentage of progress from precancerous stage to undiagnosed stage one

Percentage of regression from precancerous stage to 'clean' state through immune reaction

Progression of undiagnosed cancer from stage 2 to Stage 3

Progression of Undiagnosed cancer from stage 3 to stage 4

\section{PROGNOSIS OF diagnosed Ca. cervix}

Treatment impact/five year survival rate

Early intervention survival rate

$\begin{array}{ll}38.8 & {[1]} \\ 16.5 & {[1]} \\ 2100 & {[1]} \\ 4178 & {[1]} \\ 2635 & {[1]} \\ 60.7 & \\ 45 \text { Years } & \text { Baseline survey } \\ 7.5 y e a r s & \text { Experts opinion } \\ & \\ 40 . & \text { Baseline survey } \\ 0.81 & \\ 0 \% & \text { Expert opinion } \\ .55 & \text { Experts opinion } \\ 0.008 & \end{array}$

13.2

23.4

3.2

0.01

0.03

250

600

324

7.5

96

95

33

7 to 15 years

5

$3-10 \%$

90-97\%

$40 \%$

$80 \%$

$92 \%$

[2]

[2]

[2]

Experts opinion Experts opinion

[3]

[3]

[3].

Baseline survey Baseline survey Baseline survey

[4]

[5]

[5]

[5] [4]

$6]$

[6]
Year 2009

Assumed all eventually will die from Ca Cervix

This was considered insignificant hence not modeled.
Limited data available Limited data available Assuming a life time protection

Assuming waning off of vaccine protection after 10 years. 
Table 1 PARAMETER[S] estimates and sources (Continued)

\begin{tabular}{|c|c|c|c|}
\hline Stage 1 survival rate & $90 \%$ & {$[6]$} & .271 \\
\hline \multirow[t]{2}{*}{ Stage 2 survival rate } & $60-80 \%$ & {$[6]$} & $\begin{array}{l}\text { Average } 70 \% \text { used } \\
\text { in this model }\end{array}$ \\
\hline & & & .211 \\
\hline Stage 3 survival rate & $50 \%$ & {$[6]$} & .151 \\
\hline Stage 4 survival rate & Less than 30\% & {$[6]$} & $\begin{array}{l}30 \% \text { used in this } \\
\text { model } .091\end{array}$ \\
\hline
\end{tabular}

procedure [LEEP], cone biopsy and laser ablation at different levels of health institutions may be provided [4].

Currently the Kenyan government has a mix of policies, advocating for Abstinence [A], Be faithful [B] and the use of Visual Inspection with Acetic Acid (VIA) and Visual Inspection with Lugol'sIodine (VILLI) as screening methods in low resource settings. VIA and VILLI have been underutilized considering their low costs and simplicity of use - However VIA also has very low specificity as the cervix reacts to many other conditions including non cancerous changes, polyps and other infections $[4,5]$. Treatment interventions are expensive and may not be sustainable in a low resource setting [4].

In general, Cancer control in Kenya is an integrated evidence-based activity consisting of primary prevention, early detection, treatment and rehabilitation. However each of the interventions has its own benefits and challenges.

\section{Vaccination}

Primary vaccination against HPV infections has demonstrated high efficacy, immunogenicity and safety [6]. Since HPV is sexually transmitted, pre-exposure vaccination may be administered to both young boys and girls. However, vaccination of boys has been found to be less cost effective in a low resource setting [7] and is debatable in countries with adequate resource settings [8]. For the vaccine to be effective there must be high coverage of vaccination among pre adolescent girls and lowering of vaccine costs [6]. Research has also demonstrated that catch up vaccination usually performed among older women is effective as a preventive strategy [9]. Not all women qualify for catch up vaccination which is recommended for women between 10 to 45 years. Women who are already infected with HPV would also not benefit from vaccination [9]. HPV has over 100 sub-types; there is no single vaccine which can provide immunity against all these strains. This is compounded further by a report that even in developed economies around 15\% $-30 \%$ of women do not complete the vaccination doses $[10,11]$.

Two main vaccines are currently available in Kenya. Gardasil which costs on average $\$ 150$ [Kshs 12,000] and targets HPV types 6, 11, 16 \& 18, with some cross- protection against emerging and related HPVs 45 and 31 [12], is reported to have an effectiveness rate of $98 \%$ and the effect lasts for 4 years. Gardasil has been recommended for 9 to 26 year olds and is given in three divided doses over a period of 6 months. Cervarix which costs \$300-\$360 [approximately Kshs20,000] [12] and among HPV vaccines has been reported as the most expensive in the world of vaccination. Cervarix's effect lasts for six years on average and targets HPV types 16 and 18 . It is reported to be $92 \%$ to $100 \%$ effective with a wider age coverage of 10-45 years [13]. Even though these vaccines may not provide lifelong immunity and booster doses are required after 10 years, the probability of an immunized woman having HPV infection is lowered substantially and with this effect potentially lasting over a decade, even a single complete dose of vaccination is beneficial [13]. Despite the challenge of the high cost of vaccination and many women lacking the knowledge of cervical cancer and HPV vaccine, Kenyan women have been reported to have a positive attitude towards HPV vaccination [14].

\section{Challenges faced in cervical cancer screening}

Kenya, like other developing countries, faces a number of challenges in cervical cancer screening. The high costs associated with screening as well as a lack of information on screening, poor access to organized preventive screening services, ineffective infrastructure characterized by few existing facilities that are under-resourced, over-burdened and lack adequate equipment and staff [15]. The long distance between facilities and clients' residences increases the transport costs, clients' time costs and the cost of sending Pap smear samples to and from the processing laboratories. These factors reduce the number of clients who return for test results. Chirenje et al. [15] however argue thathealth care institutions in East and Central Africa have the necessary infrastructure for cervical cancer screening, but these facilities experience frequent shortages of materials needed for taking Pap smears. Ineffective follow-up results in poor quality data. A large number of women in Kenya lack consumer information on cervical cancer, and preventive measures including screening. Women do not receive accurate information about the actual cost of services [16] andabout $15 \%$ of the few women 
who undergo screening do not return for their test results [17].

A lack of updated cancer registries with incomplete risk factor data curtails reliable population based estimates for incidence rates, mortality rates and effectiveness of interventions [17].

Faced with all these challenges, it is important that the country adopts a coherent policy as well as alternative effective intervention strategies on cervical cancer management in Kenya.

\section{Screening in Kenya}

It is estimated that only $1-2 \%$ of women in Kenya have been screened for cervical cancer in the last five years and that only $3.2 \%$ of all women aged between 18 and 69 years are screened every 3 years [3]. Other case studies and projects have reported an estimated coverage of between $1 \%$ to $10 \%$ [18]. A number of projects on screening for cervical cancer in both urban and rural settings have been conducted. Some provided screening alone with referral of suspected cervical cancer cases to health care facilities, while others offered 'on site' immediate treatment. The effectiveness of referral to poorly equipped health care facilities with a delayed treatment period of almost six months raises the question of whether it is ethical to perform mass screening without accessing appropriate treatment services and follow up [19].

Even though there are a number of screening methods available, not all methods can be deployed in developing countries due to limited resources. The type of screening chosen by the specific country depends on a number of factors, including availability of resources, infrastructure, health-seeking behaviours, the frequency of screening and the nature of the screening test [9]. For developing countries to have effective cervical cancer screening, systematic screening coupled with treatment options must be available. These screening interventions must be integrated into the existing health systems and should be economically, socially and culturally acceptable. Cost is a major factor in considering a cervical cancer screening strategy. Goldie et al. [20] estimated the total discounted cost of screening utilizing VIA at $\$ 15$; the use of $\mathrm{HPV}$ DNA testing which required two visits was estimated at $\$ 18$ while cytological examination was estimated at \$25. It is to be noted that the low specificity of some screening methods results in false positive results which may result in unnecessary treatment and increased anxiety among women.

\section{Treatment strategies}

Treatment of cervical cancer is dependent on the stage of infection. Treatment methods include cryotherapy, Loop Electrosurgical Excision Procedure [LEEP], Cone biopsy and Laser ablation [21]. These methods are effective as long as the cervical cancer has not spread to beyond the local level. Once metastasis has commenced then other interventions must be considered. These include surgery, chemotherapy, radiation or a combination of any of the interventions. Treatment intervention of cervical cancer has been estimated to reduce mortality rate by $76 \%$ [15]. Different stages of HPV infections have different treatment costs. Goldie et al [20] estimated the cost of treatment of invasive cancer stage one at 1,552, stage two at 1,925 while distant stage which included stage 3 and 4 at 1,995 in 2000 international dollars.

\section{Why system dynamics?}

In order to overcome the above mentioned challenges of real world experiments and future uncertainties, we need to perform in silico experiments to design and test policies that cover a range of possible futures. One method that can be used is Health Systems Simulation [HSS]. HSS is the application of computer simulation to explore, understand and improve the interaction between structure and action in health care and policy as well as model the complexities of modern health services. Computer simulation has been viewed as a mature and powerful tool for modelling the health system to test how different factors may improve efficiency, effectiveness and equity in situations where it is not possible to conduct real-world experiments [22].

System Dynamic Simulation becomes a reliable way to test a hypothesis, evaluate the likely effect on policies and provide a possible answer to most myopic real life experiments. This method has been applied widely in the health care sector. Royson et al. [23], used System Dynamics to develop policies and programs in England while Fett MJ [24] used Powersims System Dynamics modelling software to model two Swedish county trials of mammographic screening and the trade-offs between participation and screening intervals [23,24]. The practice of in silico experiments and the systematic application of systems engineering approaches have been viewed as more cost-effective and have been encouraged in redesigning and improving performance of health care systems [23].

\section{Previous cervical cancer management models}

Different models have been used to evaluate cervical cancer management. Sanders and Taira [25] used decision maker software to develop a Markov model in evaluation of effectiveness and cost effectiveness of prophylactic HPV vaccine. Abbot et al. [26], used agent based simulation to demonstrate how cells acquire cancer while GoldhaberFiebert et al [27] modelled HPV for analysis of screening and vaccination in the United States and found that while screening reduced the life time risk of cervical cancer by $76 \%$, vaccination reduced the same by $75 \%$ while a 
combination of both reduced the same by $89 \%$. Goldie et al. [28] used mathematical models that demonstrated reduction of cervical cancer through both vaccination and screening.

Even though the above models have been developed and utilized in various scenarios, no benchmark exists against which a model can be evaluated in determining either the best fit of parameters or representation of disease process [29]. At the same time few if any models have focused on Kenya as a developing country. This study is therefore aimed at developing a SD model for evaluating the possible effect of primary vaccination, secondary vaccination and screening campaigns specifically for Kenya in the area of Cervical Cancer Management.

\section{Methods}

A system dynamics model was developed using iThink $^{\text {TM }}$ version 9.1.3 software package (http://www.iseesystems. com/softwares/Version913Features.aspx). Detailed model version is available as Additional file 1.

System Dynamics is a system of differential equations solved using integral calculus approximations:

$$
\operatorname{Stock}(t)=\int_{\left(t_{0}\right)}^{t}(\text { inflow-outflow }) * d t+\operatorname{Stock}\left(t_{0}\right)
$$

Where $t$ represents the stock, $t_{0}$ represents initial value of stock; dt is a time step which represents the rate of change with respect to time.

The model is an open, dynamic, deterministic, lumped compartmental model consisting of stocks and flows, with information feedbacks. Data was derived from previous published literature, cancer registries and where data was not available an expert opinion was sought. This methodology is in line with documented methodologies [30]. Table 1 provides the details and source of data used to estimate model parameters.

The choice of model and software took into consideration the availability of data, availability of software, background skills of the researchers, structure of cervical cancer, the management processes and the objectives of the study.

\section{Overview of the model structure, features and its use}

A snapshot of the model population structure is shown in Figure 1. Figure 2 shows the model's general and female population outputs. Figure 3 (showing the vaccination sector) and Figure 4 (showing the screening and treatment intervention sector) further elaborate the structure of the model.

Boxes represent population stock; clouds represent births and deaths, single arrows represent flows from one stock to the next while single circles with linking smaller arrows represent causative/influencing factors (connectors and auxiliary variables). The model comprises a female population of aging chain of girls and women with or without HPV infection. The female population was grouped into given age groups; The females were divided into seven age groups: [0-5], [4-9], [10-14], [15-24], [25-44], [45-64] and over 65 years based on age groups of published data on cervical cancer [3]. The population is stratified by mutually exclusive health states characterized by vaccinated or non-vaccinated status, HPV infection status, stage of cancer and screened or non-screened, detected or undetected cancer. The model starts with the number of infant girls [age less than 1 year] born in Kenya in the year 2010 [3]. This population is assumed to grow at the birth rate of $3.2 \%$. These girls mature to be pre-adolescent girls aged 9 years. The model assumes vaccination of pre-adolescent girls at the age of 9 years and before turning 10 years. This is because by age 9, the conversion of dormant columnar epithelium of the endo-Cervical canal into squamous epithelium has not yet occurred hence the cells are still not susceptible to HPV infection $[31,32]$. This is in line with the minimum recommended age of 9 to 12 years for pre-exposure vaccination by the Centre for Disease Control [CDC] [33] and others [34].

It is also assumed that at this age the girls are not yet sexually active. The efficacy of the vaccine was assumed to be lifelong hence the lifetime immunity against HPV once vaccinated. The rate of Primary vaccination is a factor of accessibility and the attitude of caregivers towards the primary vaccination. The [5-9] nine years age group is stratified into the primary vaccinated and nonprimary vaccinated. The population of girls who received primary vaccination permanently exit the model.

The model then follows up on the girls who did not receive primary vaccination. It is assumed that all the non primary vaccinated girls are exposed to HPV infection. As the girls progress through the aging chain, they are eligible for catch up or secondary vaccination between the ages of [10-44] years. The rate of secondary vaccination is assumed to be a function of accessibility, knowledge and attitude towards catch-up vaccination. Those receiving secondary vaccination permanently exit the model, assuming lifelong efficacy of the vaccine.

The model further assumes;

i. That all the females seeking vaccination will complete the full dose of vaccine.

ii. That $38.8 \%$ of all the never vaccinated females will acquire HPV infection based on the prevalence of HPV in Kenya.

iii. That only the females who missed both primary and secondary vaccination are eligible for screening against HPV. 


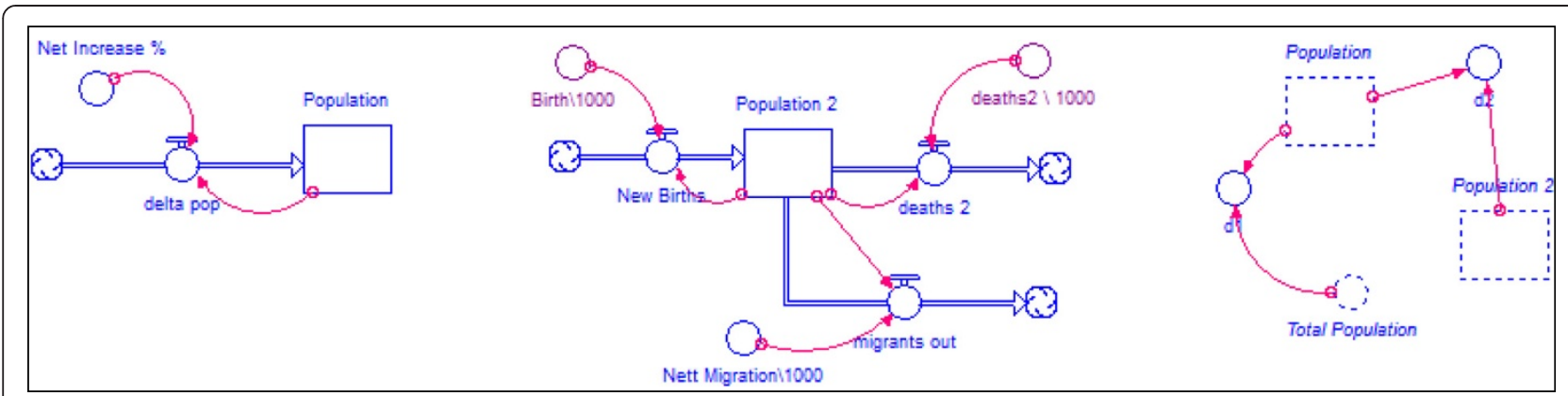

Figure 1 General population sector.

iv. That only a proportion of the women who missed both primary and secondary vaccination will undergo cervical cancer screening later in life while others will miss this vital intervention.

v. That all the HPV infections among the screened women will be detected and subjected to appropriate treatment.

vi. That HPV infection among the unscreened women will progress naturally except these women will not benefit from treatment.

vii. That a small proportion of the population of women with unscreened/undiagnosed cervical cancer may have 'accidental' opportunity for screening in the course of their seeking health services. viii. That depending on the stage of this 'accidental' screening and diagnosis, they move to the group of screened and diagnosed population and subsequently benefit from treatment interventions.

The model then follows up on the prognosis of the population of women with diagnosed and un-diagnosed
Cervical Cancer. This group of women exits the model permanently through death.

The main input variables are primary vaccination, secondary vaccination and screening rates. The potential impact of these interventions on reduction of cervical cancer cases was studied. The main output variables were: the number of women receiving primary and secondary vaccination, the number of women screened against HPV, averted cases of cervical cancer and mortality rates from cervical cancer. Disability adjusted life years (DALYs) were used to estimate the burden of disease. DALYs are used as an indicator of burden of a particular condition. DALYs are calculated by adding the total sum of years lived with disability caused by the condition otherwise referred to as Years of Life lived with disability (YLD) and years of life lost (YLL) due to early death as a consequence of the disease condition. These YLL values are based on the present value of life expectancy with a social discount rate. DALYs adjustment is based on the severity and duration of illness. One DALY is equivalent to loss of one year which would

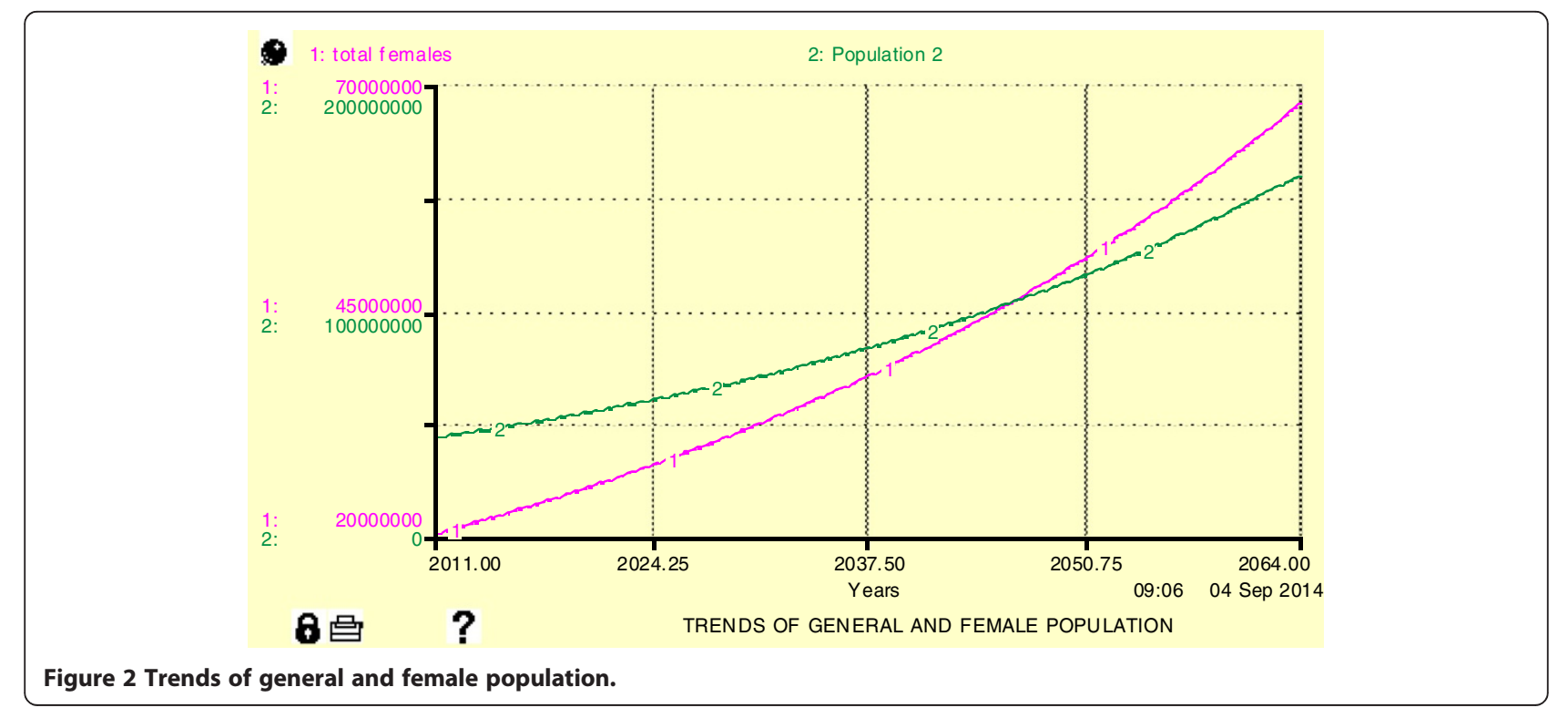




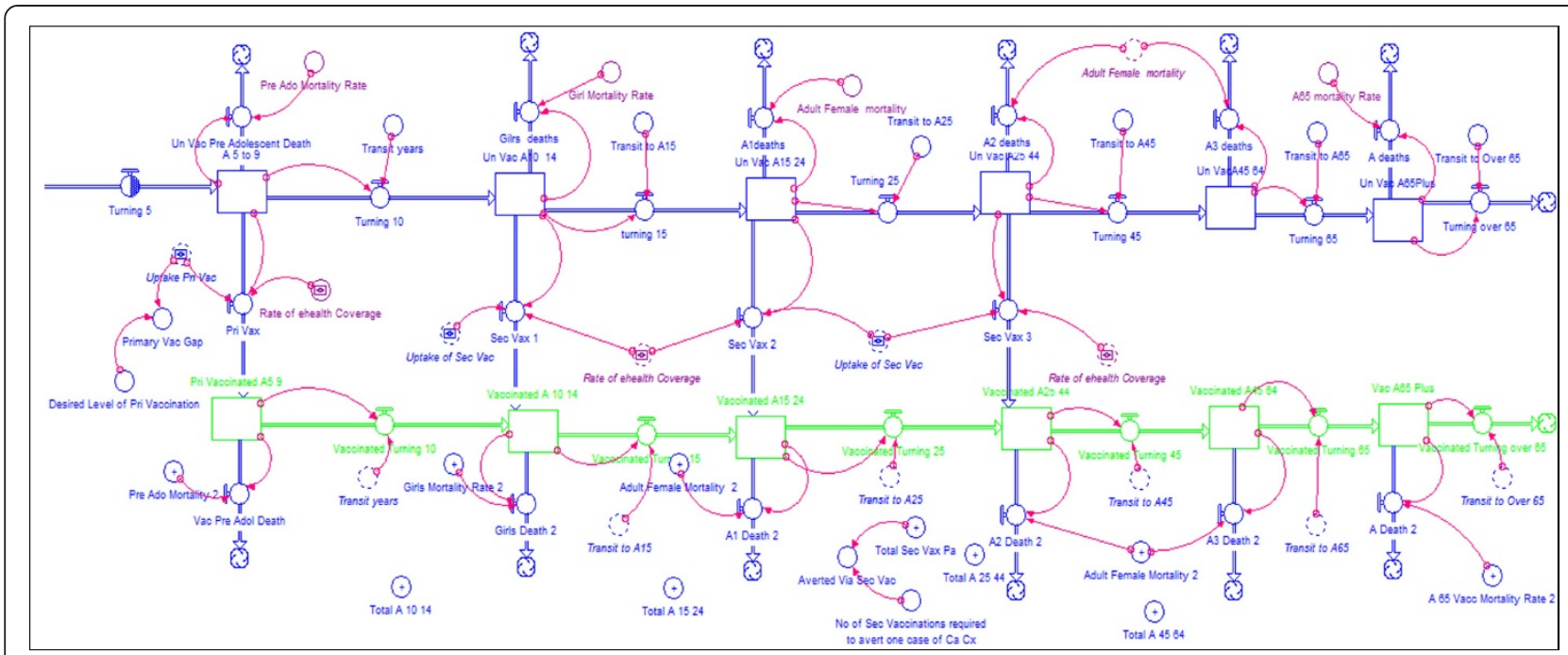

Figure 3 Snap shot of vaccination sector.

otherwise have been lived in full health. DALYs therefore are an indicator of both years of life and functional loss and hence the aim of interventions is to reduce the DALYs. DALYS are a recommended measure of health benefits in developing countries [35]. Other indicators of impact for this model include incidence rates of cancer, expected rise in cancer cases, averted cases of invasive cancer and DALYs estimates. The effects of different interventions were then studied and compared. Synergy between two or more alternative strategies was evaluated.

\section{Validation and verification of the SD Model}

The model was validated through animation, face validity, predictive validation and extreme condition tests [36]. The demographic sector of the model was first validated through checking if it could produce close estimates of referenced demographic characteristics elsewhere (http:// esa.un.org/wpp/unpp/p2k0data.asp). Error of Estimation of $30 \%$ was deemed an acceptable level. The error of estimate may be attributed to imperfect calibration and unaccounted for environmental interferences. Calibration is aimed at minimizing the error of parameter estimates [37].

\section{Sensitivity analysis}

Sensitivity analysis assessed the effect of parameter variations on model results. The level of screening, primary and secondary vaccinations was varied from 0.001 to 1.0 . A slider input device was provided in the interface of the model. For accurate integration of equations, the fourth order RungeKutta and a DT (Step Size) of 0.25 were applied.

\section{Model simulation}

Simulations were then run with different levels of parameters. The population dynamics in relation to cancer are simulated over a period of 50 years (2010-2060). It

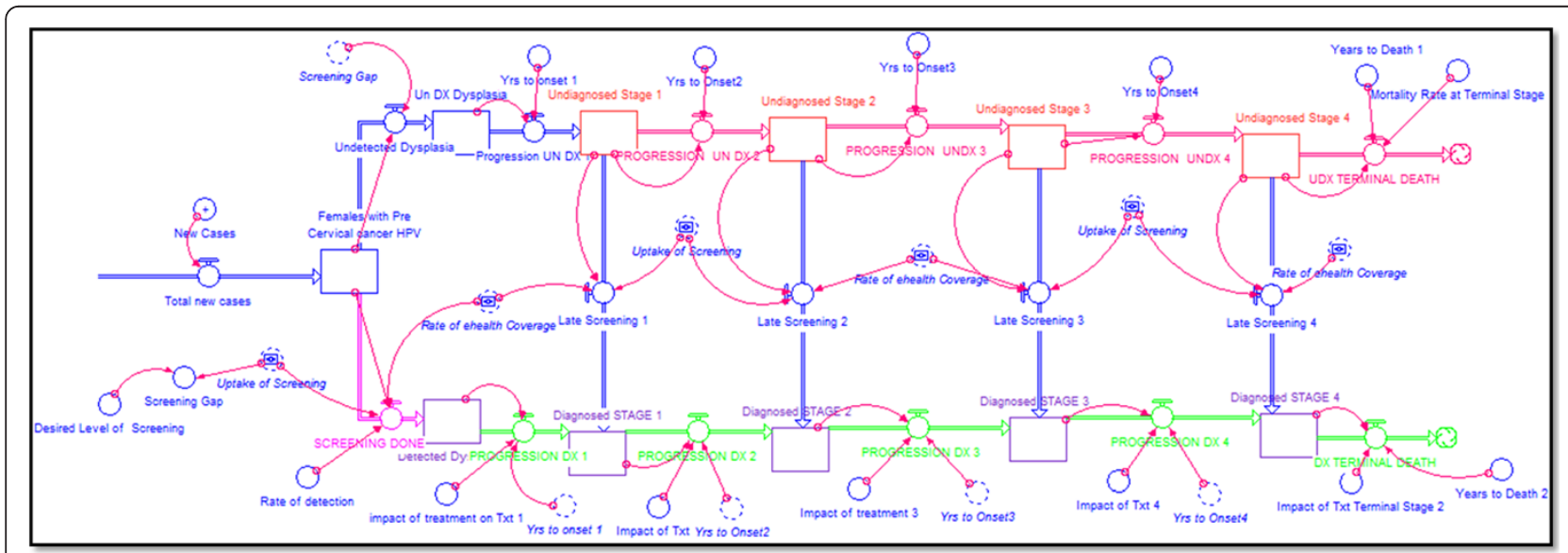

Figure 4 Snap shot of screening and treatment sector. 
is assumed that with a life expectancy of 60.9, the model follows a birth cohort to estimated life expectancy. These experiments attempt to demonstrate the current landscape of Cervical Cancer prevention and control strategies in Kenya as well as simulate possible future landscapes. A number of 'what if 'scenarios were simulated.

The prognosis of cervical cancer with and without treatment is as indicated in Table 1 . It is assumed that once the disease has progressed to stage 3 , treatment options are geared towards improving quality of life and palliative care rather than elimination of the infection [19].

The simulated results of different proposed interventions are presented. The policy experiments include;

1. Business as usual (base-case) scenario.

2. Varying the levels of primary vaccination.

3. Varying the levels of catch up/secondary vaccination.

4. Varying the levels of screening.

5. Combining and varying screening and vaccination levels.

Even though the model can perform different levels of experiment values, for the purposes of this paper, the WHO-CHOICE standard geographical coverage of 50\%, $80 \%$ and $95 \%$ of eligible cases receiving intervention are utilized. A 'realistic' scenario of 30\% coverage was also simulated based on a study done by Royston et al. who used $30 \%$ as realistic coverage of health intervention in France [38]. The results were compared against a basecase scenario.

\section{Structure of cervical cancer management model}

Figure 1 shows the population growth dynamics with a birthrate of $3.2 \%$, the trends of total female population in comparison to the general population. The simulation results were compared with projections of the Kenyan population by the United Nations on (http://esa.un.org/ unpd/wpp/unpp/p2k0data.asp). The results as well as the respective error of estimations are shown in Table 2. The error of estimate can be attributed to the changing birthrate over time due to family planning practice, increasing levels of education, urbanization and economic empowerment [39]. The model however utilized a constant birth rate.

\section{Results}

The Model was run using iThink ${ }^{\mathrm{Tm}}$ software and the results were presented in the form of graphs/figures. Figure 5 shows simulated Annual trends of diagnosed, undiagnosed, new cases, total cases of cervical cancer and total deaths due to cancer. This is taken as the base case scenario, using age standardized incidence rates per 100,000 Population. The average screening rate of $3.2 \%$ was used. The rate of primary and secondary vaccinations could not be established and expert opinion estimated coverage at $0.1 \%$ and $0.3 \%$ respectively and the rate of screening was taken at 3.2\% [3]. A birth rate of 3.2 and an average life expectancy rate of 60.9 years were utilized in the simulation. These trends closely mirror other projections which estimated the annual death rate among cervical cancer clients at 65\%, and estimated 2,454 new cases and 1676 deaths each year [40].

Figure 6 shows trends of new cases of cervical cancer at status quo. The women aged 55 to 64 years have the largest number of new cases of cervical cancer. This age group also has the highest level of age specific incidence rate estimated at 105/100,000 women [3].

Figure 7 shows the trends of undiagnosed cervical cancer among women who missed primary vaccination, secondary vaccinations and screening. Undiagnosed stage 1 has the highest number of undiagnosed patients. This may be attributed to the slower rate of disease progression from stage one to stage two. Undiagnosed Stage 4 has the least number of clients among the undiagnosed group; this may be attributed to the fast rate of progression from stage 3 to stage 4 as well as the high death rate (Approximately 65\%) of clients at this stage as the clients rarely benefit from Medical Intervention.

Figure 8. Shows trends of cases of diagnosed cervical cancer.

For diagnosed cervical cancer patients, the majority are in stage one. This may be attributed to the treatment impact at this stage with probability of regression and Cure. Diagnosed stage 4 has more clients compared to the undiagnosed stage 4 . This may be attributed to early intervention at stage one and two among the diagnosed group as well as delayed death at stage four of diagnosed patients due to treatment interventions. The treatment interventions delay progression from one stage to the next.

\section{Output indicators}

Cost utility analysis was used as indicated by changes in Disability Adjusted Life Years [DALYs] and Total Cost of averted DALYs. DALYs consisted of Years of Life Lost (YLL) and Years of Life Lived with Disability (YLD).

The cost per averted DALY was based on a simplified calculation based on the total cost of intervention divided by the DALYs averted.

DALYs = YLD + YLL. Fox-Rushby and Hanson [35] calculation method was adopted Table 3.

\section{Impact of different interventions on DALY trends Combined interventions}

The model sought to estimate the impact of combined intervention strategies on the trends of DALYs and averted DALYs 
Table 2 Female population trends by age groups

\begin{tabular}{|c|c|c|c|c|}
\hline Year & $\begin{array}{l}\text { Age } \\
\text { group }\end{array}$ & $\begin{array}{l}\text { Projected } \\
\text { population }\end{array}$ & $\begin{array}{l}\text { Simulated } \\
\text { population }\end{array}$ & $\begin{array}{l}\text { Error of } \\
\text { estimation }\end{array}$ \\
\hline 2010 & $0-4$ & 3345 & 3045 & $-9.0 \%$ \\
\hline 2015 & $0-4$ & 3584 & 2635 & $-26.5 \%$ \\
\hline 2020 & $0-4$ & 3792 & 2959 & $-22.0 \%$ \\
\hline 2025 & $0-4$ & 4024 & 3322 & $-17.4 \%$ \\
\hline 2030 & $0-4$ & 4315 & 3720 & $-13.8 \%$ \\
\hline 2035 & $0-4$ & 4606 & 4156 & $-9.8 \%$ \\
\hline 2040 & $0-4$ & 4849 & 4634 & $-4.4 \%$ \\
\hline 2045 & $0-4$ & 5029 & 5162 & $2.7 \%$ \\
\hline 2050 & $0-4$ & 5183 & 5747 & $10.9 \%$ \\
\hline 2055 & $0-4$ & 5290 & 6396 & $20.9 \%$ \\
\hline 2060 & $0-4$ & 5396 & 7117 & $31.9 \%$ \\
\hline 2010 & $5-9$ & 2887 & 2859 & $-1.0 \%$ \\
\hline 2015 & $5-9$ & 3276 & 3238 & $-1.2 \%$ \\
\hline 2020 & $5-9$ & 3525 & 3222 & $-8.6 \%$ \\
\hline 2025 & $5-9$ & 3742 & 3472 & $-7.2 \%$ \\
\hline 2030 & $5-9$ & 3981 & 3845 & $-3.4 \%$ \\
\hline 2035 & $5-9$ & 4277 & 4288 & $0.3 \%$ \\
\hline 2040 & $5-9$ & 4573 & 4787 & $4.7 \%$ \\
\hline 2045 & $5-9$ & 4821 & 5339 & $10.8 \%$ \\
\hline 2050 & $5-9$ & 5004 & 5949 & $18.9 \%$ \\
\hline 2055 & $5-9$ & 5159 & 6625 & $28.4 \%$ \\
\hline 2060 & $5-9$ & 5266 & 7374 & $40.0 \%$ \\
\hline 2010 & $10-14$ & 2421 & 2421 & $0.0 \%$ \\
\hline 2015 & $10-14$ & 2855 & 2880 & $0.9 \%$ \\
\hline 2020 & $10-14$ & 3250 & 3063 & $-5.8 \%$ \\
\hline 2025 & $10-14$ & 3505 & 3224 & $-8.0 \%$ \\
\hline 2030 & $10-14$ & 3724 & 3488 & $-6.3 \%$ \\
\hline 2035 & $10-14$ & 3965 & 3847 & $-3.0 \%$ \\
\hline 2040 & $10-14$ & 4263 & 4278 & $0.3 \%$ \\
\hline 2045 & $10-14$ & 4560 & 4768 & $4.6 \%$ \\
\hline 2050 & $10-14$ & 4809 & 5314 & $10.5 \%$ \\
\hline 2055 & $10-14$ & 4992 & 5921 & $18.6 \%$ \\
\hline 2060 & $10-14$ & 5148 & 6593 & $28.1 \%$ \\
\hline 2010 & $15-24$ & 4204 & 4204 & $0.0 \%$ \\
\hline 2015 & $15-24$ & 4509 & 4607 & $2.2 \%$ \\
\hline 2020 & $15-24$ & 5192 & 5108 & $-1.6 \%$ \\
\hline 2025 & $15-24$ & 6026 & 5523 & $-8.4 \%$ \\
\hline 2030 & $15-24$ & 6684 & 5938 & $-11.2 \%$ \\
\hline 2035 & $15-24$ & 7163 & 6435 & $-10.2 \%$ \\
\hline 2040 & $15-24$ & 7628 & 7045 & $-7.6 \%$ \\
\hline 2045 & $15-24$ & 8171 & 7773 & $-4.9 \%$ \\
\hline 2050 & $15-24$ & 8770 & 8618 & $-1.7 \%$ \\
\hline 2055 & $15-24$ & 9316 & 9577 & $2.8 \%$ \\
\hline
\end{tabular}

Table 2 Female population trends by age groups

(Continued)

\begin{tabular}{|c|c|c|c|c|}
\hline 2060 & $15-24$ & 9750 & 10653 & $9.3 \%$ \\
\hline 2010 & $25-44$ & 5041 & 4929 & $-2.2 \%$ \\
\hline 2015 & $25-44$ & 6129 & 5726 & $-6.6 \%$ \\
\hline 2020 & $25-44$ & 7057 & 6551 & $-7.2 \%$ \\
\hline 2025 & $25-44$ & 7911 & 7387 & $-6.6 \%$ \\
\hline 2030 & $25-44$ & 8879 & 8209 & $-7.5 \%$ \\
\hline 2035 & $25-44$ & 10018 & 9040 & $-9.8 \%$ \\
\hline 2040 & $25-44$ & 11348 & 9923 & $-12.6 \%$ \\
\hline 2045 & $25-44$ & 12663 & 10898 & $-13.9 \%$ \\
\hline 2050 & $25-44$ & 13802 & 11994 & $-13.1 \%$ \\
\hline 2055 & $25-44$ & 14850 & 13236 & $-10.9 \%$ \\
\hline 2060 & $25-44$ & 15936 & 14639 & $-8.1 \%$ \\
\hline 2010 & $45-64$ & 2013 & 2013 & $0.0 \%$ \\
\hline 2015 & $45-64$ & 2376 & 2747 & $15.6 \%$ \\
\hline 2020 & $45-64$ & 2822 & 3497 & $23.9 \%$ \\
\hline 2025 & $45-64$ & 3471 & 4264 & $22.8 \%$ \\
\hline 2030 & $45-64$ & 4349 & 5044 & $16.0 \%$ \\
\hline 2035 & $45-64$ & 5352 & 5833 & $9.0 \%$ \\
\hline 2040 & $45-64$ & 6228 & 6636 & $6.5 \%$ \\
\hline 2045 & $45-64$ & 7070 & 7465 & $5.6 \%$ \\
\hline 2050 & $45-64$ & 8033 & 8338 & $3.8 \%$ \\
\hline 2055 & $45-64$ & 9167 & 9275 & $1.2 \%$ \\
\hline 2060 & $45-64$ & 10479 & 10297 & $-1.7 \%$ \\
\hline 2010 & $65+$ & 580 & 580 & $0.0 \%$ \\
\hline 2015 & $65+$ & 703 & 751 & $6.8 \%$ \\
\hline 2020 & $65+$ & 895 & 979 & $9.4 \%$ \\
\hline 2025 & $65+$ & 1121 & 1239 & $10.6 \%$ \\
\hline 2030 & $65+$ & 1356 & 1520 & $12.1 \%$ \\
\hline 2035 & $65+$ & 1617 & 1814 & $12.2 \%$ \\
\hline 2040 & $65+$ & 1987 & 2118 & $6.6 \%$ \\
\hline 2045 & $65+$ & 2540 & 2432 & $-4.2 \%$ \\
\hline 2050 & $65+$ & 3283 & 2760 & $-15.9 \%$ \\
\hline 2055 & $65+$ & 4119 & 3108 & $-24.5 \%$ \\
\hline 2060 & $65+$ & 4888 & 3483 & $-28.7 \%$ \\
\hline
\end{tabular}

i. At a base case scenario.

ii. 30\% (realistic Coverage) of Primary Vaccination, Secondary Vaccination and screening.

iii. 50\% Coverage of Primary Vaccination, Secondary Vaccination and screening.

iv. 80\% Coverage of Primary Vaccination, Secondary Vaccination and screening.

v. 95\% Primary Vaccination, Secondary Vaccination and screening. 


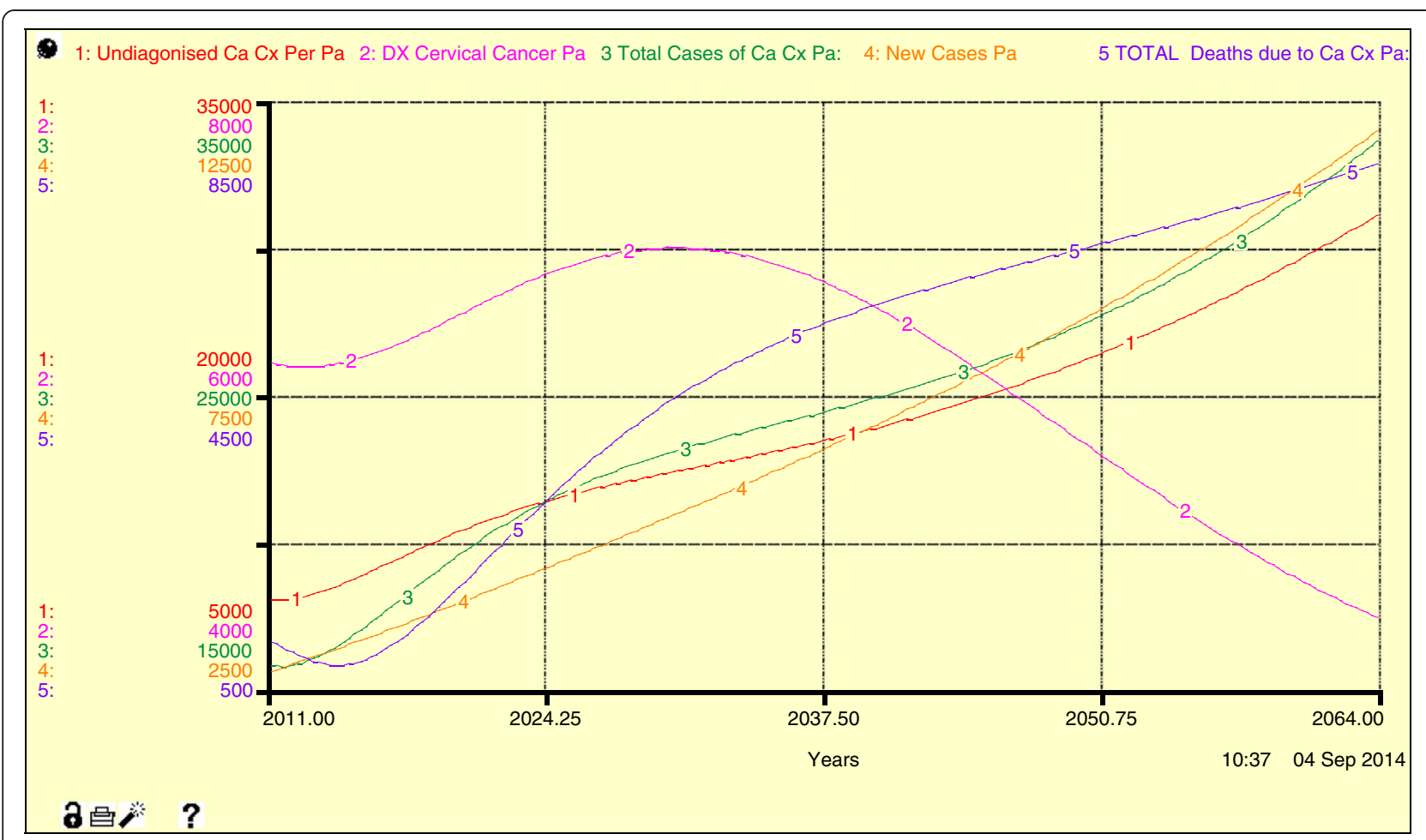

Figure 5 Trends of, undiagnosed cases (1) diagnosed cases (2), total cases of cervical cancer (3), new cases (4) and total deaths from cervical cancer (5).

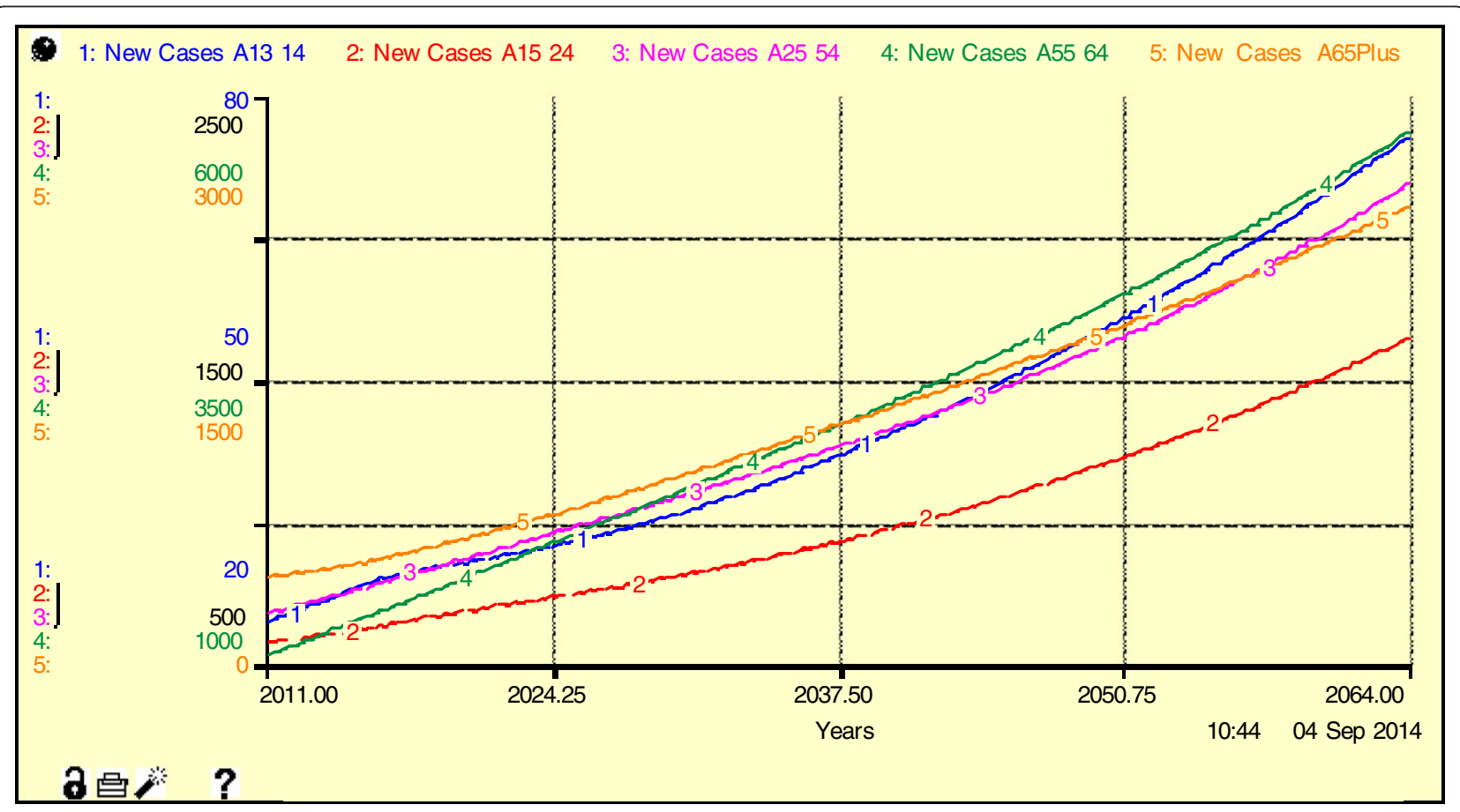

Figure 6 Trends of new cases at base case scenario. 


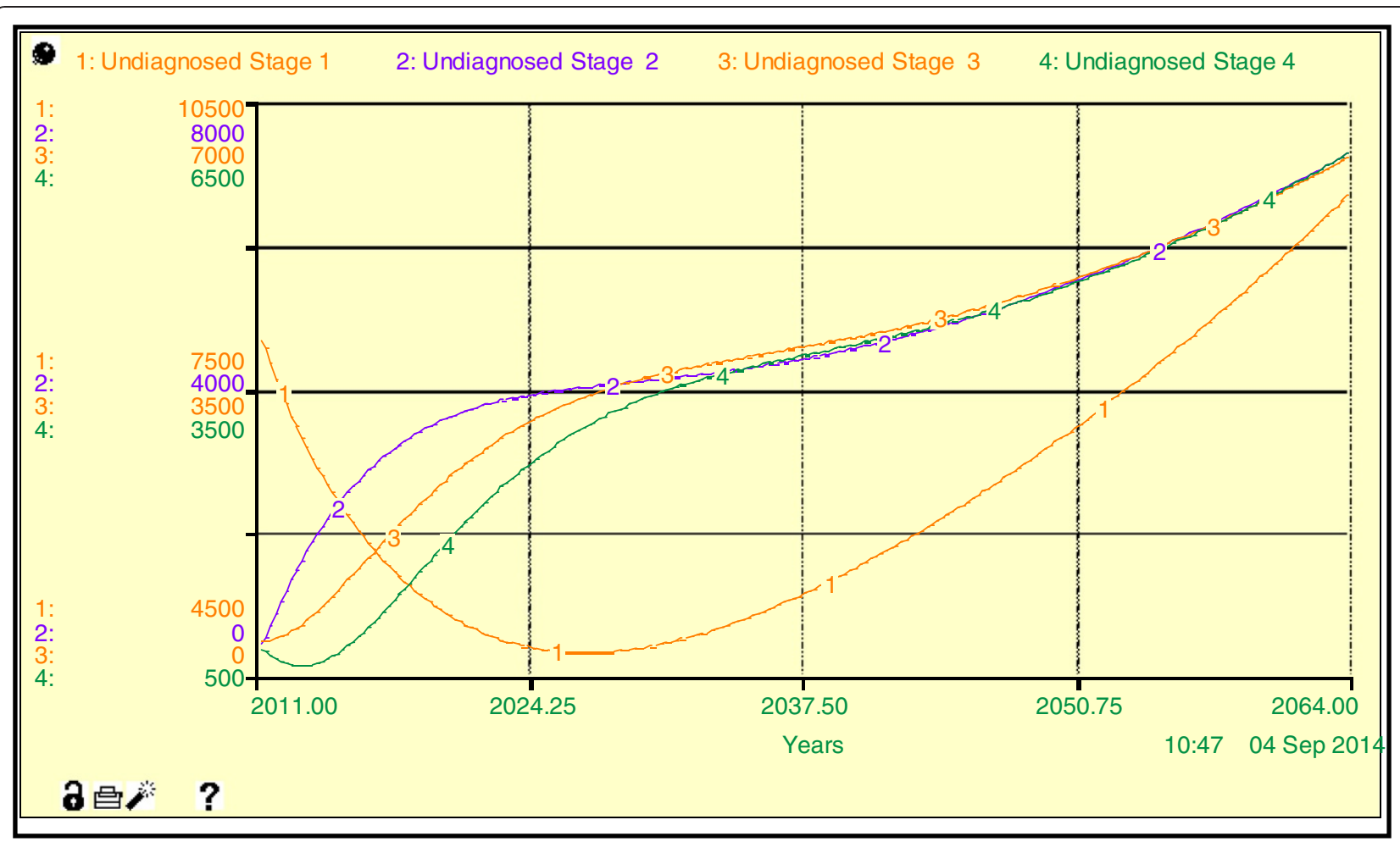

Figure 7 Trends of cases of undiagnosed cervical cancer at base case scenario.

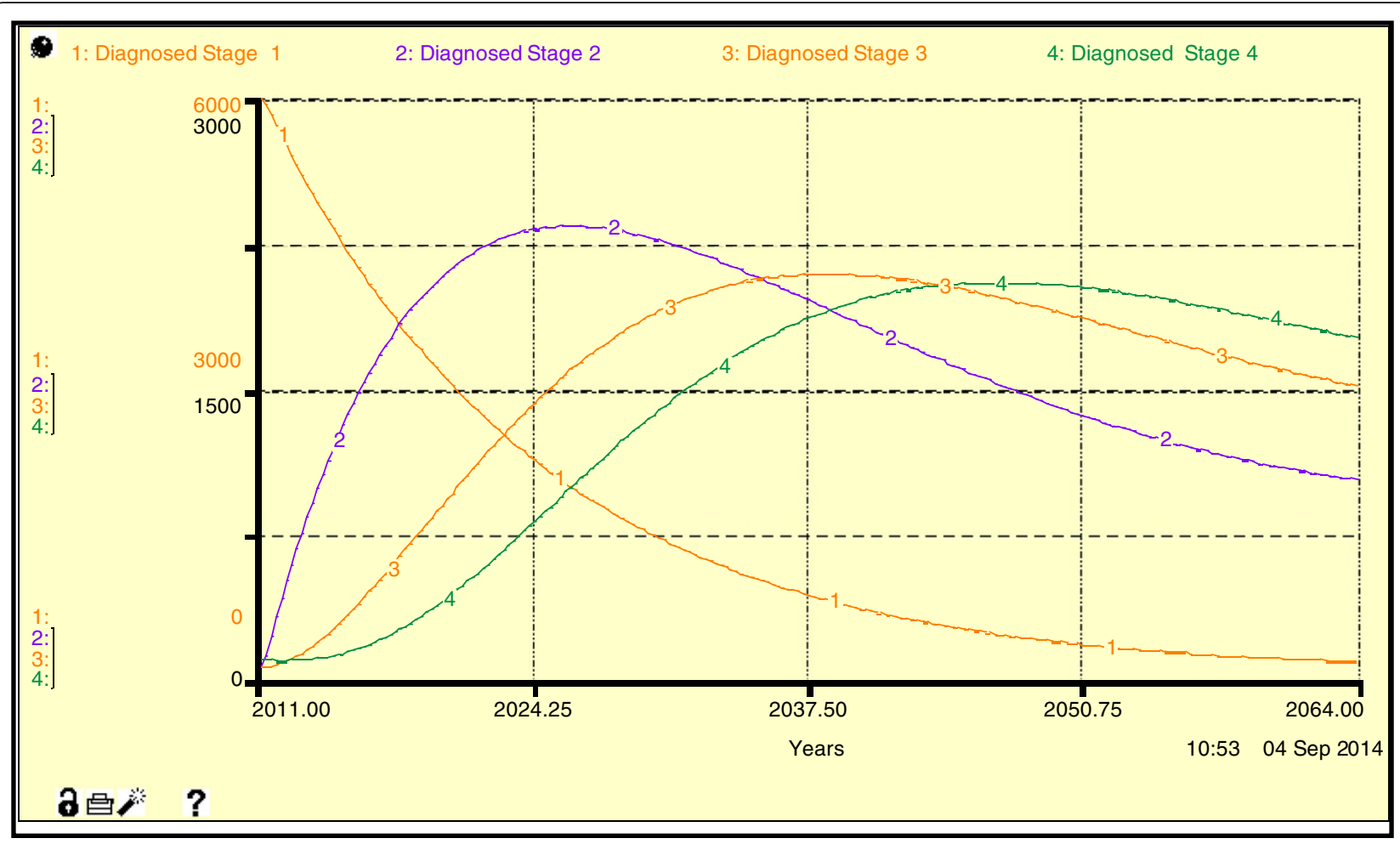

Figure 8 Trends of cases of diagnosed cervical cancer at base case scenario. 
Table 3 Illustrates the variables of Fox-Rushby and Hanson [35] calculation method

\begin{tabular}{ll}
\hline [K] Age weighting modulation factor & YLD \\
[W] is a constant & 1 \\
[y] Discount rate expressed as decimals & 0.1658 \\
[Alpha] Age at diagnosis of cervical cancer & 0.03 \\
[Beta] Parameter for age weighting function & 45 \\
[l] Average duration of disability & 0.04 \\
[D] Disability Index of cervical cancer & 15 \\
& 0.81 \\
[alpha 2] Age of death & YLL \\
[life2] Standard expectation of life at age of & 60.7 \\
diagnosis with cervical cancer & 15.7 \\
\hline
\end{tabular}

Figure 9, demonstrates expected trends of DALYs and DALYs averted at Base Case Scenario. In the year 2060, only 94,676 DALYs would be averted at the current state of intervention in management of cervical cancer. At a realistic coverage of $30 \%$ of the three interventions, 4,454,100 DALYs will be averted, while 5,269,002would be averted at 50\% coverage levels with $80 \%$ and $95 \%$ coverage levels accounting for 5,891,677 and 6,088,880 respectively (Figure 10). This would then mean that even a realistic coverage of the three interventions would be a significant target in management of Cervical Cancer in Kenya.

Figure 9, shows a general reduction in DALYs with increase in coverage rates a reflection of the impact of the three interventions.

\section{Impact of primary vaccinations}

The model sought to estimate the impact of primary vaccination. In this model, Primary vaccination refers to vaccination at 9 years of age only. Other models have set primary vaccination from age 9 to age $12[33,41,42]$. It has been reported that 250 vaccinations among girls less that 12 years are required to avert one case of cervical cancer assuming immunity of a life span and 600 with waning immunity after 10 years [25].

\section{The impact of different rates of primary vaccination} coverage

Figure 11 show predicted levels of DALYs averted in different levels of coverage of primary vaccination coverage. The DALYs averted increase with increase of coverage of primary vaccination.

\section{Impact of secondary vaccination}

The impact of Secondary Vaccination on DALYs averted was simulated. It was noted that 324 Secondary vaccinations are required to avert one case of cervical cancer among eligible women [43]. This is a $29.6 \%$ increase in the number of vaccinations requiredin comparison with primary vaccination and hence an increase in cost of vaccination. For the purposes of this model, Secondary Vaccination has been defined to cover the women aged 10 to 44 years. Other studies have set the age bracket at different figures thirty three $[41,42]$.

Figure 12, shows simulated trends of DALYs averted at different levels of secondary vaccination.

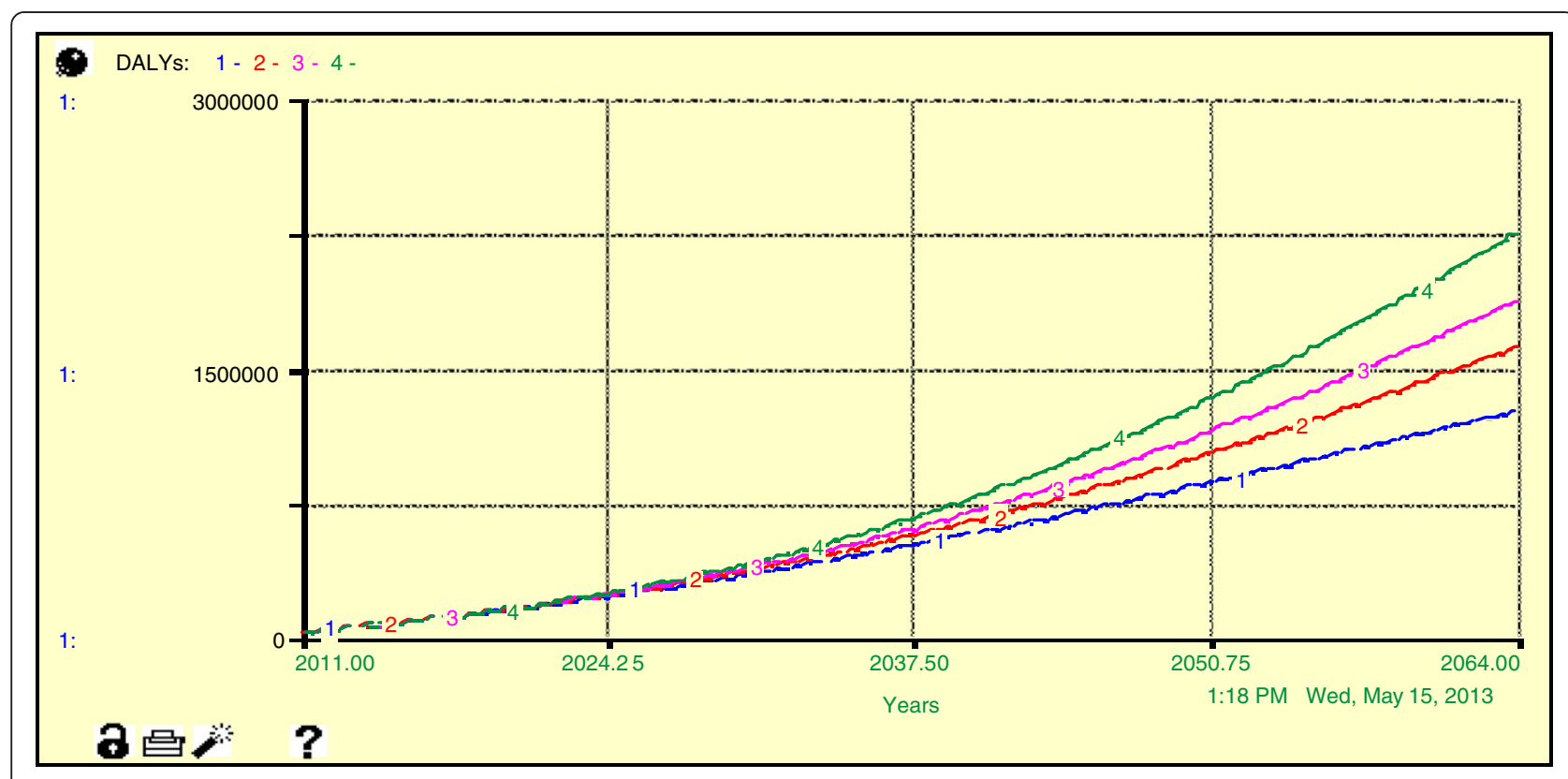

Figure 9 Trends of DALYs at base case scenario, at $30 \%, 50 \% .80 \%$ and $95 \%$ coverage rates of the three interventions. 


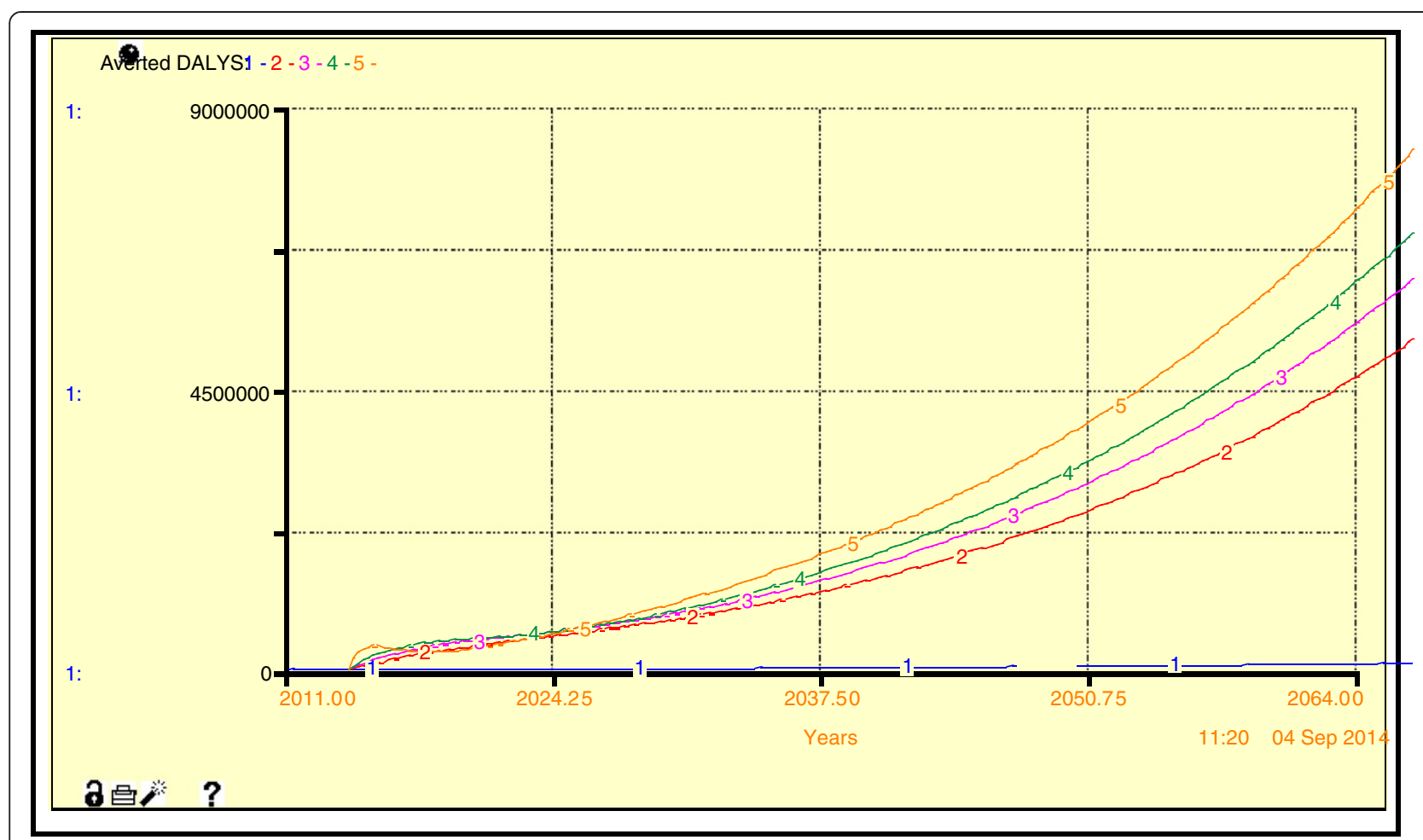

Figure 10 Averted DALYS at base case (1), 30\% coverage (2), 50\% coverage (3), 80\% coverage (4) and $95 \%$ coverage (5).

Averted DALYS: $1-2-3-4-5-$

$1:$

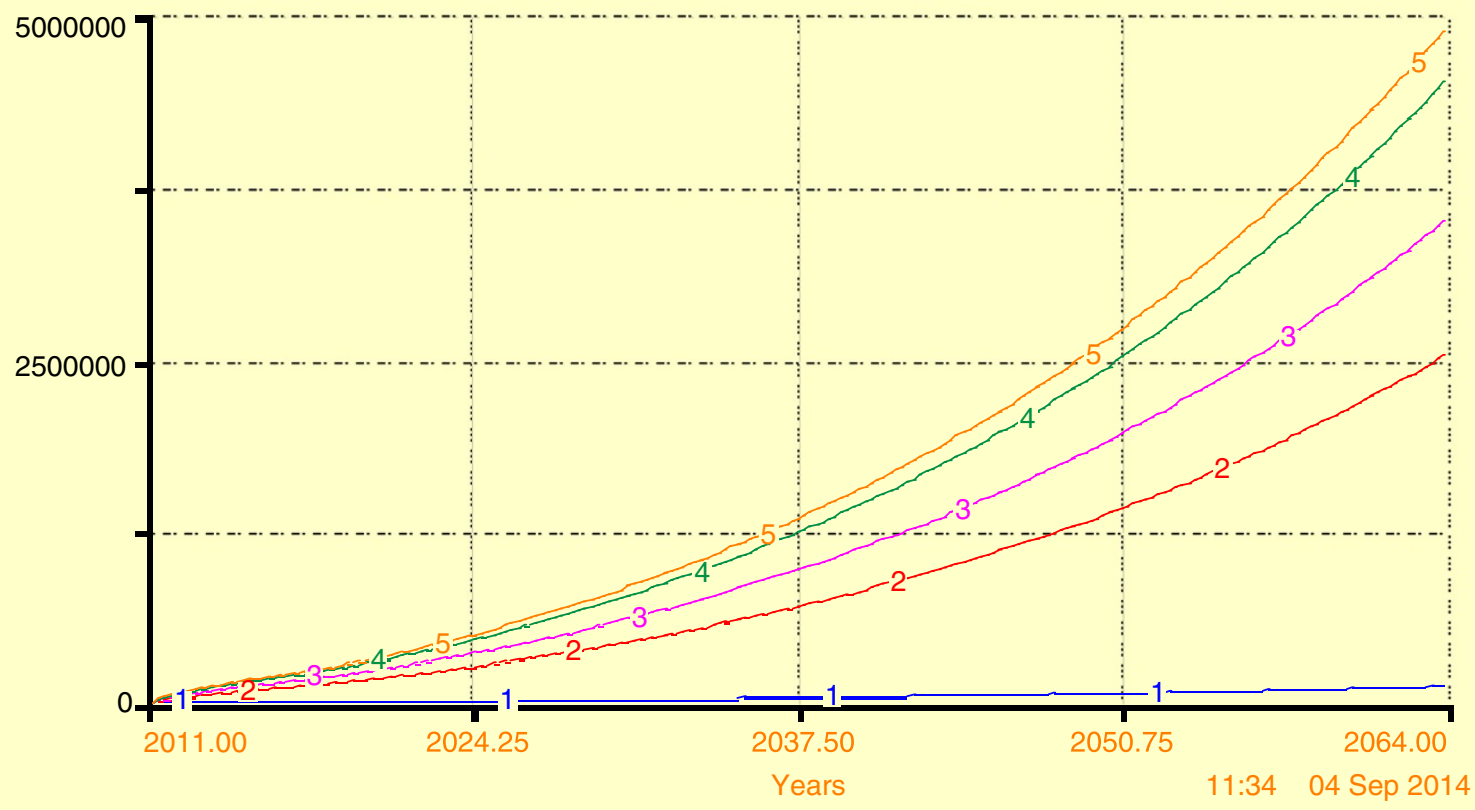

2 晃菜?

Figure 11 Impact of primary vaccination on DALYs averted at base case (1), 30\% (2), 50\% (3), 80\% (4), 95\% (5) coverage levels. 
Total Averted DALYs: 1 - 2 - 3 - 4 - 5 -

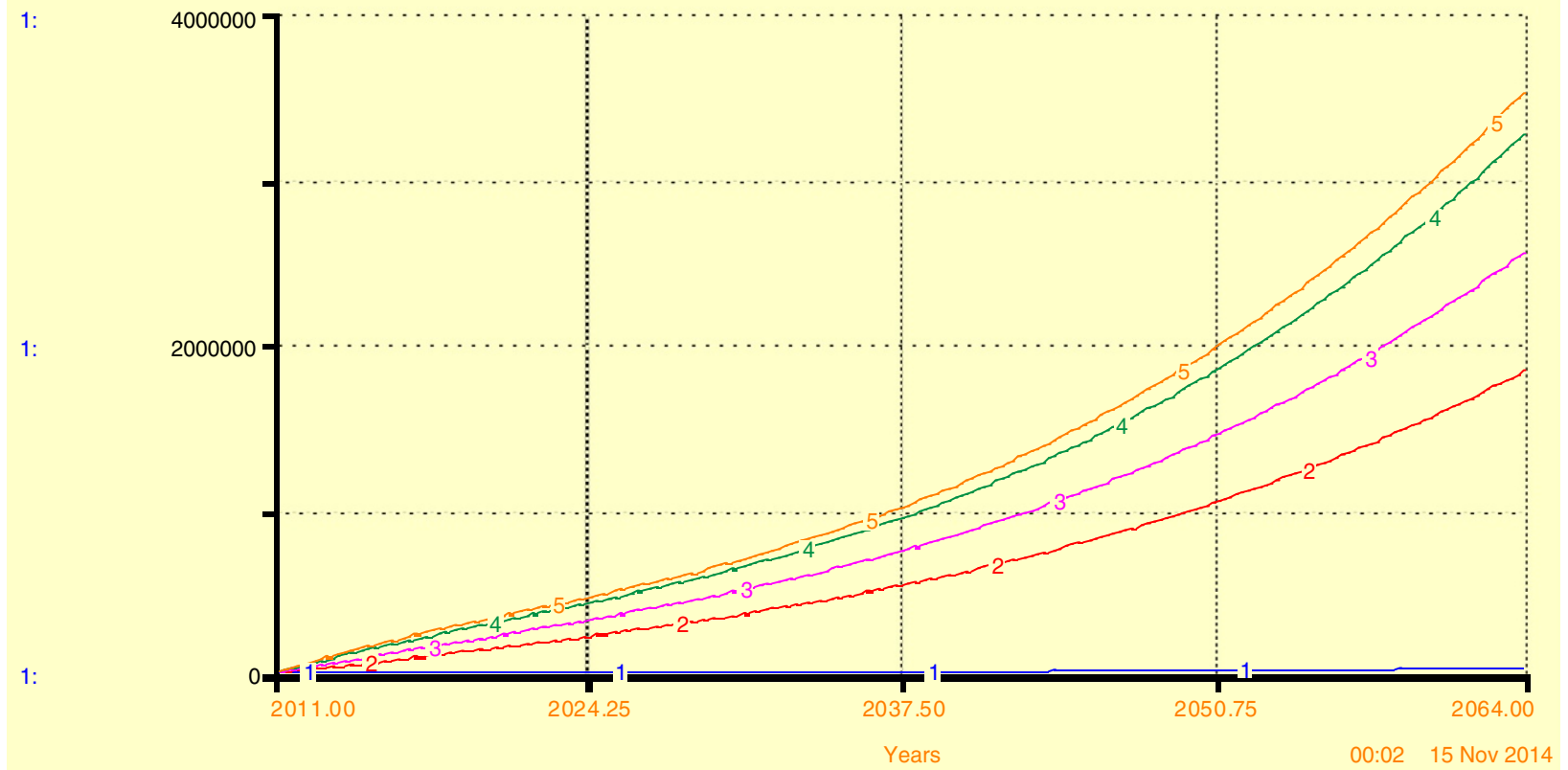

2昌米?

Figure 12 Impact of secondary vaccination on DALYs averted at base case (1), 30\% (2), 50\% (3), 80\% (4) and 95\% (5) coverage levels.

Averted DALYS: $1-2-3-4-5-$

1:

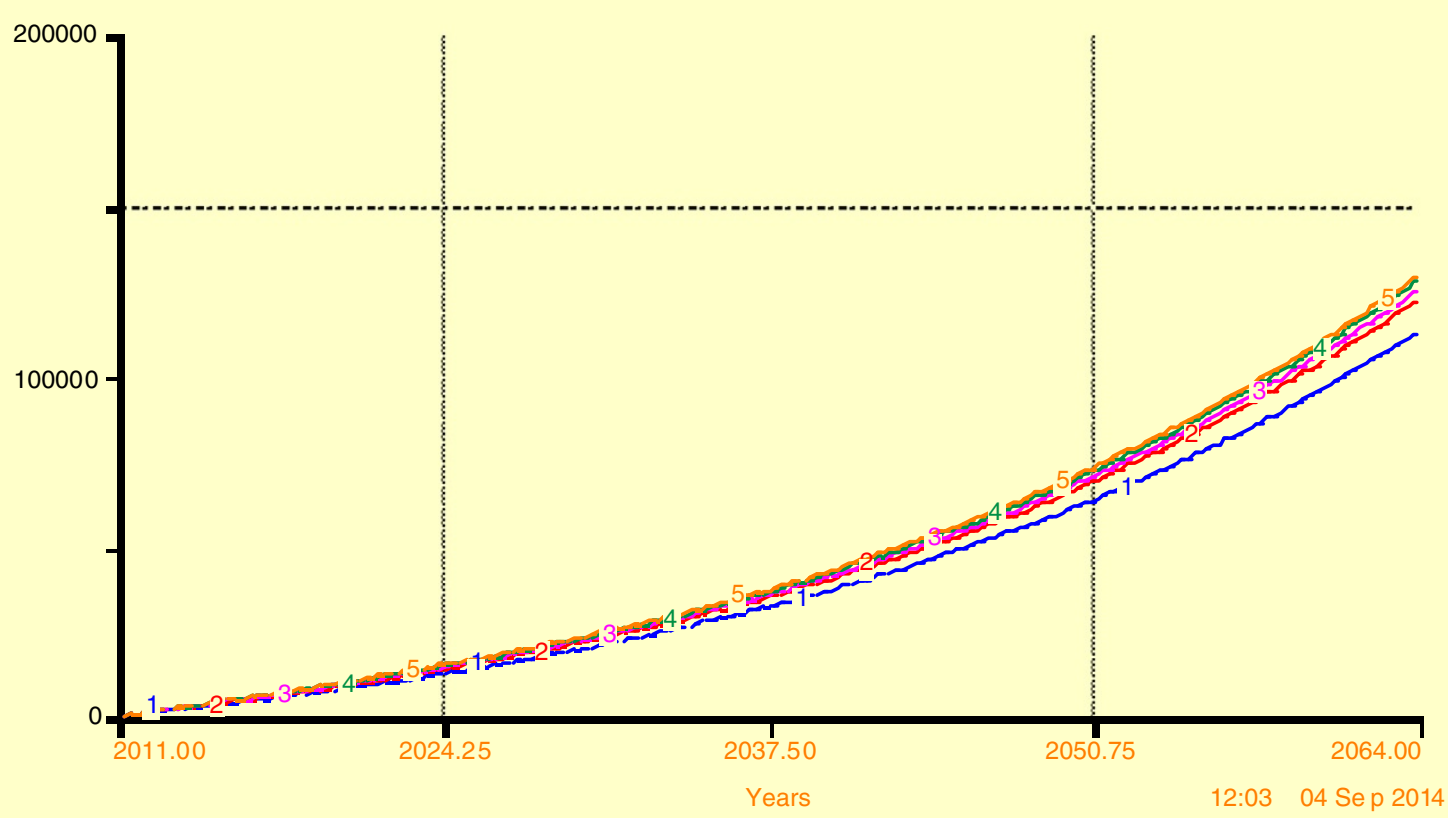

昌米？

Figure 13 Impact of different levels of screening coverage on DALYs averted. 
Cost \$ Per DALY AVERTED: 1 - 2 -

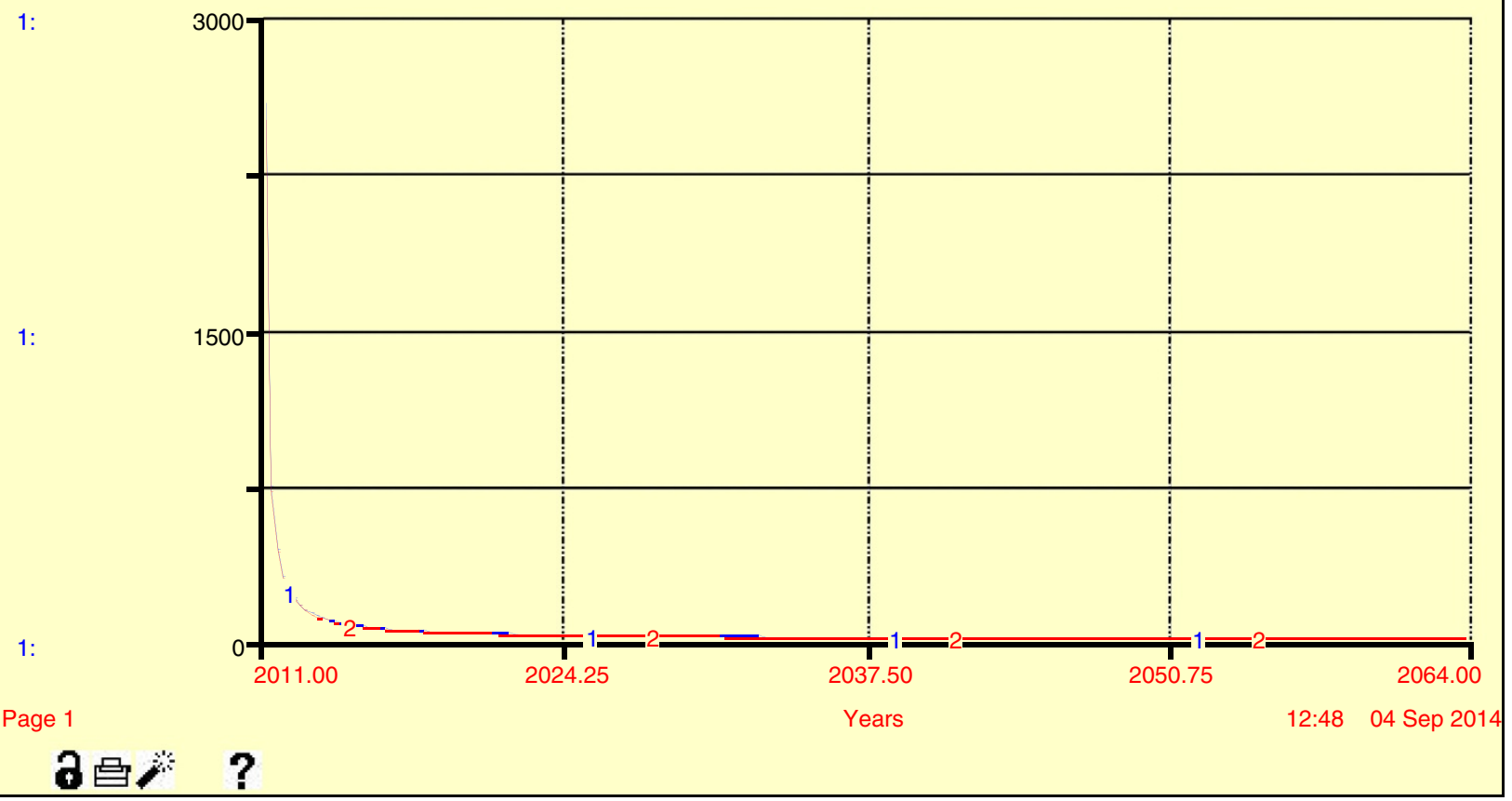

Figure 14 Cost per averted DALY at base case (1) and at $30 \%$ coverage of the primary vaccination, secondary vaccination and screening interventions.

The impact of secondary vaccination will be realized earlier in time in comparison to the impact of primary vaccination. The results in Figure 11 and Figure 12 demonstrated that catch up vaccination would be a more effective short term approach in the prevention of HPV infections as compared to primary vaccination. Over the simulated 50 year period, secondary vaccination would result in aversion of $52 \%$ to $56 \%$ more DALYs in comparison to primary vaccination. These figures however can change depending on the set age limits of both primary and secondary vaccination.

\section{Impact of screening}

Screening intervention has been identified as an effective preventive measure as long as it is done systematically, covering a large proportion and is done concurrently with treatment. Apart from resources needed, effectiveness of screening is also affected by such factors as the number of tests required, the sensitivity and specificity of screening methods available as well as the recommended screening intervals [44]. This model assumes effective cervical cancer screening coverage.

It is assumed that the proportion of girls who were not vaccinated are at risk of HPV infection. This is the group which is subjected to HPV screening and that all the women who have been confirmed to have HPV are subjected to appropriate treatment options. The base case rate of $0.1 \%$ of primary and $0.3 \%$ secondary vaccination remains.

Screening coverage was shown to reduce DALYs. . The rate of change however reduced after a $50 \%$ coverage rate as noted from Figure 13 . However at a realistic coverage (30\% of all the interventions) screening contributed to less averted DALYs in comparison to primary and secondary vaccination. Screening would contribute $85 \%$ to $89 \%$ less DALYs than secondary vaccination and $68 \%$ to $75 \%$ less averted DALYS than primary vaccination. The impact of screening is expected to be realized later in comparison with primary vaccination and catch up vaccination.

Generally the simulation results demonstrate that, an increase in the level of coverage of the different interventions, resulted into an increase in the reduction of DALYs as well as an increase in DALYs averted.

Figure 14 compares the cost of averting each DALY at base case and at a realistic coverage of the three interventions. The cost per DALY averted decreases significantly with increases in intervention coverage.

By the Year 2060, and at a realistic coverage, secondary vaccination would account for the largest portion of averted cases (at 98\%) followed by primary vaccination (1.2\%) while screening would contributed the lowest with less than $1 \%$. 


\section{Discussion}

This model assessed the possible impact of primary vaccination, secondary vaccination and screening campaigns in the management of cervical cancer in Kenya. Current levels of coverage were compared with different intervention scenarios including a 'realistic' coverage of $30 \%$ of the three interventions. The model confirmed effectiveness of the three strategies in management of cervical cancer; however the possible impact of the interventions varied according to the various scenarios simulated.

Secondary vaccination against HPV was found to have the highest impact of the three choices of intervention. Different studies have emphasized the potential impact of vaccination as an intervention in reduction of HPV infection and cervical cancer mortality [21]. Secondary vaccination would account for a reduction of over $50 \%$ incidence rates. This is consistent with Baussano et al. [45] who simulated a 50\% reduction in HPV prevalence after the introduction of catch up vaccination. It is noted that even with higher primary vaccination coverage, the impact of vaccination is realized only after $10-15$ years. This is consistent with findings of Franco and Cuzick [13]. After rolling out an extensive HPV vaccination a recent study in Australia reported a reduction ranging from 0.1 to $0.38 \%$ in both low grade and high grade abnormalities in a period of 3 years [46]. Five years later the AustralianNational HPV vaccine programs reported success in reduction of not only HPV cervical cancer related lesions but also a reduction of $9.65 \%$ in genital warts [47].

Primary Vaccination can only achieve its potential impact if it reaches all vulnerable groups. Nationwide School based vaccination programs may go along way in meeting this need [13] The trade off in vaccination intervention must be considered in relation to age specific incidences, vaccination coverage rate, efficacy of the vaccine and risk of viral re-infection among others [46,48]. A challenge of resistance to vaccination due to low acceptability among respondents is possible. This has been reported in France withthe uptake of hepatitis vaccine [38] as well as HPV vaccination uptake in USA where less than $50 \%$ of teenage girls completed the three doses of HPV vaccine. The reasons associated with resistance included some parents of teenagers feeling that the vaccine was not needed, safety concerns and fear of increase in sexual activity, convenience of completion of the vaccine and lack of factual information on the vaccine [49]. It is important to note that women in Kenya and Botswana have been reported to have high levels of acceptability of HPV vaccines $[14,50]$. This is a strength in these country which could be used as a basis for HPV vaccine. Low income countries have been documented to have a more supportive environment and the school based HPV vaccination programs model has been documented to result in a high coverage rate [51].
Primary vaccination must take into account economic considerations. It has been argued that an HPV vaccination exercise may not be economically viable in developing economies due to the high cost of vaccination, the un-sustainability of such an economic endeavor by GAVI as well as other more competing health priorities $[52,53]$. However HPV vaccine may be the most effective measure in the future $[54,55]$.

Screening was shown to have the lowest impact of the three choices of intervention in terms of the number of cervical cancer cases averted and the impact on reduction of DALYs. However it is important to note that the primary purpose of screening is early diagnosis and treatment and not necessarily a preventive measure. Cervical cancer screening has been considered as an effective method of reduction in cervical cancer mortality, accounting for a $70 \%$ reduction in mortality rate in developed countries and contradicting results in developing countries [17]. The Nordic and some European countries have succeeded in a reduction of cervical cancer where systematic screening was done. However cervical cancer screening has been reported to have a low rate of success attributed to a number of factors which include low test sensitivity of HPV testing, uneven access to screening and coverage, lack of follow up in women with abnormal results, poor treatment and poor quality of care among others [13]. It has been suggested that in a low resource setting, women of over 30 years should have at least one screening done. However this test has a $30 \%-50 \%$ probability of false negative results [18].

The simulated results of this model concur with the theory that screening may have minimal effect in control of cervical cancer with coverage of less than $50 \%$. The results support Goldie et al. [48], who reported that coverage of over $50 \%$ of HPV screening resulted in minimal change to the cervical cancer rate. Denny et al. [17] suggested that for successful Cervical Cancer screening in a low resource setting to take place, a number of essential requirements must be met. These include but are not limited to low cost, low screening technology, diagnosis and treatment offered on site, wide coverage of the majority of at risk women, appropriate educational programs for both clients and health care workers as well as a built in mechanism for evaluation of screening programs. It is important to not only have massive screening but also have surveillance programs with recall and follow up embedded in existing health services [18]. It has been argued that it is unethical to provide screening services in the absence of a treatment option [19]. Screening has also been found to be less acceptable with some women describing it as 'invasive' to their privacy and being against the cultural expectations [56]. These factors pose a challenge to screening as an intervention. 
The long term effect of the negative attitude towards screening interventions should not be ignored.

\section{Limitations of the study}

The model did not make a distinction between regularly screened and occasionally screened women. Efficacy of vaccine was assumed to be life-long, however vaccine effects last for a limited period of time, usually around 10 years, and hence a booster is required later. If efficacy of the vaccine is poor, then there is poor impact on reduction of cervical cancer. The need for a vaccination booster was not included in the model. The impact of male circumcision and vaccination of Boys against HPV were also not modelled. HPV has been known to cause other genital cancers. The effects of HPV vaccination on these other cancers were not simulated and hence it may be necessary to develop a model which incorporates the impact on all these other cancers.

There is limited cervical cancer epidemiological data available in Kenya. Therefore this population based model relied mostly on aggregate point data which did not allow for probability variations. Even though population based models are easier to construct, they may miss out on the uniqueness of individual clients and hence may not allow the history of each individual client to be tracked. The model was not differentiated by socioeconomic status hence socioeconomic status interventions could not be established.

All three interventions occur in a dynamic context affected by Information Communication and Technology (ICT) among others. The model was limited in its ability to include all other possible confounding variables. However the model allows for modification to accommodate for new research findings.

\section{Recommendations}

As a matter of policy, Kenya should consider secondary vaccination and primary vaccination as a matter of priority. Screening should be complementary to primary and secondary vaccination. This is based on the assumption that the country could afford all options. With the proposed financial support of HPV vaccine by GAVI, the expected cost will be between $\$ 5$ and $\$ 15$ which is close to the average cost of screening. There is a need to develop a model on the implication of vaccination in developing economies, and Africa in particular.

\section{Conclusion}

This model generated reasonable estimates in the evaluation of the effects of different interventions on cervical cancer management in Kenya. Interim cervical cancer management policy has been derived. The model charts informed debate leading to development of new consensus policy on screening and vaccination. Cervical cancer needs to be managed and monitored continuously with screening being implemented as a complimentary intervention to vaccination. Kenya as a country needs to consider implementing catch up and primary vaccination as an urgent measure to curb cervical cancer.

\section{Additional file}

Additional file 1: System dynamics model of cervical cancer vaccination and screening interventions in Kenya developed via ithink $^{\mathrm{TM}}$.

Competing interests

The authors declare that they have no competing interests.

\section{Authors' contributions}

LWK designed the study, analyzed the data and drafted the manuscript. GM, GPP and AR designed the study; and critically reviewed and revised the manuscript for important intellectual content. All authors read and approved the final manuscript.

\section{Acknowledgements}

We acknowledge The National Council of Science and Technology (NCST) Kenya for funding this research. Stephen Hughes for reviewing and editing the Manuscript as a Native English Speaker.

\section{Author details}

${ }^{1}$ School of Nursing Sciences, University of Nairobi, P.O BOX

19676-KNH-00202, Nairobi, Kenya. ${ }^{2}$ Centre of Health Informatics, University of New South Wales, Cliffbrook House, 45 Beach St, Coogee, Sydney, NSW 2052, Australia. ${ }^{3}$ Health and Information Science, University of Victoria, PO Box 3050 STN CSC, Victoria, BC V8W 3P5, Canada. ${ }^{4}$ School of Mathematics, University of Nairobi, P.O Box 30196-GPO-00100, Nairobi, Kenya.

Received: 6 September 2014 Accepted: 4 November 2014 Published: 27 November 2014

\section{References}

1. Forouzanfar MMH, Foreman KK, Delossantos AM, Lozano R, Lopez AD, Murray CJ, Naghavi M: Breast and cervical cancer in 187 countries between 1980 and 2010: a systematic analysis. Lancet 2011, 378(9801):1461-1484. Available at: http://www.ncbi.nlm.nih.gov/pubmed/21924486. Accessed March 3, 2013.

2. McAdam M, Sakita J, Tarivonda L, Pang J, Frazer $\|_{\text {: }}$ Evaluation of a cervical cancer screening program based on HPV testing and LLETZ excision in a low resource setting. PLoS One 2010, 5(10):e13266. Available at: http://www. pubmedcentral.nih.gov/articlerender.fcgi?artid=2951361\&tool=pmcentre z\&rendertype=abstract. Accessed May 9, 2013.

3. WHO/ICO: Information Centre on HPV and Cervical Cancer (HPV Information Centre): Human Papillomavirus and Related Cancers in Kenya; Summary Report; 2010. [12th September 2012]. Available at http://s3.amazonaws.com/zanran_ storage/www.who.int/ContentPages/82032616.pdf.

4. Health P, Ministry S, Services M: Integrating the Management of STIS/RT/S into Reproductive Health Services, Pocket Handbook. Nairobi: Republic of Kenya. Available at: http://nascop.or.ke/library/STI/Integrating\%20STI-RTI\%20into\% 20RH\%20services\%20-\%20Handbook\%20for\%20Service\%20Providers.pdf.

5. Ministry of Public Health and Sanitation and Ministry of Medical Services: National Cervical cancer prevention Program: Strategic Plan 2012-2015; 2012:1-38. Avaialble at: https://www.k4health.org/toolkits/kenya-health/ national-cervical-cancer-prevention-program-strategic-plan-2012-2015.

6. Biddlecom A, Bankole A, Patterson KA: Vaccine for cervical cancer: reaching adolescents in sub-Saharan Africa. The Lancet 2006, 367(9519):1299-1300. 22 April 2006 Available at: http://www.thelancet.com/journals/lancet/article/ PIIS0140-6736\%2806\%2968555-3/fulltext doi:10.1016/S0140-6736(06)68555-3.

7. Kim JJ, Andres-Beck B, Goldie SJ: The value of including boys in an HPV vaccination programme: a cost-effectiveness analysis in a low-resource setting. Br J Cancer 2007, 97(9):1322-1328. Available at: http://www. pubmedcentral.nih.gov/articlerender.fcgi?artid=2360471\&tool=pmcentrez\&rendertype=abstract. Accessed March 12, 2013. 
8. Elbasha EH, Dasbach EJ, Insinga RP: Model for assessing human papillomavirus vaccination strategies. Emerg Infect Dis 2007, 13(1):28-41.

9. Kim JJ, Brisson M, Edmunds WJ, Goldie SJ: Modeling cervical cancer prevention in developed countries. Vaccine 2008, 26(Suppl 1):K76-K86.

10. Sinka K, Kavanagh K, Gordon R, Love J, John A, Donaghy M, Robertson C: Achieving high and equitable coverage of adolescent HPV vaccine in Scotland. J Epidemiol Community Health 2014, 68:57-63. doi:10.1136/jech2013-202620. Available at: http://jech.bmj.com/cgi/content/long/jech-2013202620v1. Accessed 11 November, 2014

11. Kumar $V$, Whynes D: Explaining variation in the uptake of HPV vaccination in England. BMC Public Health 2011, 11(1):172. Available at: http://www. biomedcentral.com/1471-2458/11/172/. Accessed August 7, 2013.

12. Henley P: Preventing Preventable Cervical Cancer in Kenya. Backgrounder No. 38; 2012. September 10, 2012 Available at: http://www.africaportal.org/ articles/2012/09/10/preventing-preventable-cervical-cancer-kenya.

13. Franco EL, Cuzick J: Cervical cancer screening following prophylactic human papillomavirus vaccination. Vaccine 2008, 26:A16-A23. Available at: http://linkinghub.elsevier.com/retrieve/pii/S0264410X07013849. Accessed May 9, 2013.

14. Becker-Dreps S, Otieno W, Brewer N: HPV vaccine acceptability among Kenyan women. Vaccine 2010, 28(31):4864-4867. Available at: http://www. sciencedirect.com/science/article/pii/S0264410X10007322. Accessed July 31, 2013.

15. Chirenje ZM, Rusakaniko S, Kirumbi L, Ngwalle EW, Makuta-Tlebere P, Kaggwa S, Makoae L: Situation analysis for cervical cancer diagnosis and treatment in east, central and southern African countries. Bull World Health Organ 2001, 79(99):127-132. Available at: http://www.scielosp.org/scielo. php?pid=S0042-96862001000200007\&script=sci_arttext. Accessed July 12, 2013.

16. Gatune J, Nyamongo I: An ethnographic study of cervical cancer among women in rural Kenya: is there a folk causal model? J Gynecol Cancer 2005, 5:1049-1059. Available at: http://onlinelibrary.wiley.com/doi/10.1111/ j.1525-1438.2005.00261.x/full. Accessed August 5, 2013.

17. Denny L, Quinn M, Sankaranarayanan R: Chapter 8: screening for cervical cancer in developing countries. Vaccine 2006, 24(Suppl 3):S3/71-77.

18. Gakidou E, Nordhagen S, Obermeyer Z: Coverage of cervical cancer screening in 57 countries: Low average levels and large inequalities. PLoS Med 2008, 5:6.

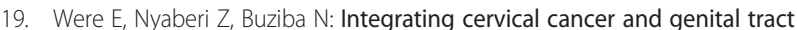
infection screening into mother, child health and family planning clinics in Eldoret, Kenya. Afr Health Sci 2010, 10(1):58-65. Available at: http://www. ajol.info/index.php/ahs/article/view/55939. Accessed August 7, 2013.

20. Goldie S: Cost-effectiveness of cervical-cancer screening in five developing countries. N Engl J 2005, 353(20):2158-2168. Available at: http://www.nejm. org/doi/full/10.1056/nejmsa044278. Accessed August 1, 2013.

21. Maine D, Hurlburt S, Greeson D: Cervical cancer prevention in the 21st century: cost is not the only issue. Am J Public Health 2011, 101(9):1549-1555. Available at: http:/www.ncbi.nlm.nih.gov/pubmed/21778496. Accessed May 9, 2013.

22. Heffernan M, McDonnell G: In "silico' intervention experiments for the health system". Intern Pap 2012, For details contact http://www.chi.unsw. edu.au/CHIweb.nsf/page/Health+System+Simulation.

23. Royston G, Dost A, Townshend J, Turner H: Using system dynamics to help develop and implement policies and programmes in health care in England. System Dynamics Review 1999, 15:293-313. doi:10.1002/(SICI)10991727(199923) 15:3<293::AID-SDR169>3.0.CO;2-1 Availabe at: http://online library.wiley.com/doi/10.1002/\%28SICI\%291099-1727\%28199923\%2915:3\% 3C293::AID-SDR169\%3E3.0.CO;2-1/pdf.

24. Fett MJ: Computer modelling of the Swedish two county trial of mammographic screening and trade offs between participation and screening interval. J Med Screen 2001, 8(1):39-45.

25. Sanders GD, Taira AV: Cost-effectiveness of a potential vaccine for human papillomavirus. Emerg Infect Dis 2003, 9:37-48.

26. Abbott RG, Forrest S, Pienta KJ: Simulating the hallmarks of cancer. Artif Life 2006, 12:617-634.

27. Goldhaber-Fiebert JD, Stout NK, Ortendahl J, Kuntz KM, Goldie SJ, Salomon JA: Modeling human papillomavirus and cervical cancer in the United States for analyses of screening and vaccination. Popul Health Metr 2007, 5.

28. Goldie SJ, Goldhaber-Fiebert JD, Garnett GP: Public health policy for cervical cancer prevention: the role of decision science, economic evaluation, and mathematical modeling. (HPV Vaccines and Screening in the Prevention of Cervical Cancer.). Vaccine 2006, 24(Suppl 3):S3/155-63.
29. Kim JJ, Kuntz KM, Stout NK, Mahmud S, Villa LL, Franco EL, Goldie SJ: Multiparameter calibration of a natural history model of cervical cancer. Am J Epidemio/ 2007, 166(2):137-150. Available at: http://www.ncbi.nlm.nih. gov/pubmed/17526866. Accessed March 26, 2013.

30. Homer JB, Hirsch GB: System dynamics modeling for public health: background and opportunities. Am J Public Health 2006, 96(3):452-458. Available at: http://www.pubmedcentral.nih.gov/articlerender.fcgi?artid= 1470525\&tool=pmcentrez\&rendertype=abstract. Accessed March 18, 2013.

31. Martens JE, Smedts FMM, Ploeger D, Helmerhorst TJM, Ramaekers FCS, Arends JW, Hopman AHN: Distribution pattern and marker profile show two subpopulations of reserve cells in the endocervical canal. Int J Gynecol Pathol Off J Int Soc Gynecol Pathol 2009, 28:381-388.

32. Di Bonito L, Bergeron C: Cytological screening of endocervical adenocarcinoma. Ann Pathol 2012, 32:e8-e14.

33. Situations S: Bivalent human papillomavirus vaccine (HPV2, cervarix) for Use in females and updated HPV vaccination recommendations from the advisory committee. cdc gov 2010, 59:626-629. Available at: http://www.cdc.gov/MMWR/ preview/mmwrhtml/mm5920a4.htm. Accessed August 12, 2013.

34. Jin XW, Lipold L, Sikon A, Rome E: Human papillomavirus vaccine: safe, effective, underused. Cleve Clin J Med 2013, 80(1):49-60. Available at: http://www.ncbi.n/m.nih.gov/pubmed/23288945. Accessed October 1, 2013.

35. Fox-Rushby A J, Hanson K: Calculating and presenting disability adjusted life years (DALYs) in cost-effectiveness analysis. Health Policy Plan 2001 16(3):326-331.

36. Wakeland WW, Hoarfrost M: The case for thoroughly testing complex system dynamic models. MA, Boston: 23rd International Conference of the System Dynamics Society; 2005. Available at: http://works.bepress.com/wayne_wakeland/16.

37. Corner S: Standard error vs . Standard error of measurement. 1999, 3(April):20-25.

38. Ribassin-Majed L, Lounes R, Clémençon S: Efficacy of vaccination against HPV infections to prevent cervical cancer in France: present assessment and pathways to improve vaccination policies. PLoS One 2012, 7(3):e32251. Available at: http://www.pubmedcentral.nih.gov/articlerender.fcgi?artid=329 9653\&tool=pmcentrez\&rendertype=abstract. Accessed March 6, 2013.

39. Blacker J, Opiyo C, Jasseh M, Sloggett A, Ssekamatte-Ssebuliba J: Fertility in Kenya and Uganda: a comparative study of trends and determinants. Popul Stud (NY) 2005, 59(3):355-373. Available at: http://www.ncbi.nlm.nih. gov/pubmed/16249155. Accessed October 4, 2013.

40. Ministry of Public Health and Sanitation and Ministry of Medical Services: National Cervical Cancer Prevention Program, Strategic Plan 2012-2015. Available at https://www.k4health.org/sites/default/files/National\%20Cervical \%20Cancer\%20Prevention\%20Program_Strategic\%20Plan.pdf.

41. De Visser R, Waites L, Parikh C, Lawrie A: The importance of social norms for uptake of catch-up human papillomavirus vaccination in young women. Sex Health 2011, 8(3):330-337.

42. Milne RJ, Vander Hoorn S, Kulasingam S, Tan AL: Economic evaluation of female vaccination with a quadrivalent human papillomavirus vaccine in New Zealand. Value Heal 2007, 10:A6-A6.

43. Brisson M: Estimating the number needed to vaccinate to prevent diseases and death related to human papillomavirus infection. Can Med 2007, 177(5):2-6. Available at: http://www.canadianmedicaljournal.ca/content/177/5/ 464.short. Accessed October 5, 2013.

44. Bingham A, Bishop A, Coffey P: Factors affecting utilization of cervical cancer prevention services in low-resource settings. Saludpública 2003 45(Suppl 3):S408-S416. Available at: http://www.scielosp.org/scielo.php? script=sci_arttext\&pid=S0036-36342003000900015. Accessed August 7, 2013.

45. Baussano I, Lazzarato F, Ronco G, Dillner J, Franceschi S: Benefits of catch-up in vaccination against human papillomavirus in medium- and low-income countries. Int J Cancer 2013, 133(8):1876-1881.

46. Brotherton J, Fridman M, May C: Early effect of the HPV vaccination programme on cervical abnormalities in Victoria, Australia: an ecological study. Lancet 2011, 377:2085-2092. Available at: http://www.sciencedirect. com/science/article/pii/S0140673611605515. Accessed August 11, 2013.

47. Fairley CK, Hocking JS, Gurrin LC, Chen MY, Donovan B, Bradshaw CS: Rapid decline in presentations of genital warts after the implementation of a national quadrivalent human papillomavirus vaccination programme for young women. Sex Transm Infect 2009, 85:499-502.

48. Goldie S, Diaz M, Kim S, Levin C: Mathematical models of cervical cancer prevention in the Asia Pacific region. Vaccine 2008, 26(Suppl 1):M17-M29. Available at: http://www.sciencedirect.com/science/article/pii/S0264410X 08007433. Accessed October 5, 2013. 
49. Bartlett JA, Peterson JA: The uptake of human papillomavirus (HPV) vaccine among adolescent females in the united states: a review of the literature. J Sch Nurs Off Publ Natl Assoc Sch Nurses 2011, 27:434-446.

50. DiAngi YT, Panozzo C a, Ramogola-Masire D, Steenhoff AP, Brewer NT: A Cross-Sectional Study of HPV Vaccine Acceptability in Gaborone, Botswana. Grinsztejn BGJ, ed. PLoS One 2011, 6(10):e25481. Available at: http://dx.plos.org/10.1371/journal.pone.0025481. Accessed April 17, 2013.

51. Tsu V: Taking HPV, vaccination to national scale: building on experience to date. Int J Gynecol Obstet 2012, 119:S252.

52. Kane MA, Serrano B, De Sanjosé S, Wittet S: Implementation of human papillomavirus immunization in the developing world. Vaccine 2012, 30(Suppl 5):F192-F200.

53. Ouedraogo N, Müller O, Jahn A, Gerhardus A: Human papillomavirus vaccination in Africa. Lancet 2011, 378(9788):315-316. Available at: http:// www.ncbi.nlm.nih.gov/pubmed/21784261. Accessed May 9, 2013.

54. Hessel L: Introduction of vaccination against human papillomavirus in developing countries: update and perspectives. Med Trop Rev du Corps sante Colon 2009, 69:323-326.

55. Bosch FX, Castellsagué X, De Sanjosé S: HPV and cervical cancer: screening or vaccination? Br J Cancer 2008, 98:15-21.

56. Kivuti-Bitok L, Pokhariyal G, Roudsari AV, McDonnell G: An exploration of opportunities and challenges facing cervical cancer managers in Kenya. BMC Res 2013, 6(1):1. Available at: BMC Research Notes. Accessed August 11, 2013.

doi:10.1186/1478-7547-12-26

Cite this article as: Kivuti-Bitok et al: System dynamics model of cervical cancer vaccination and screening interventions in Kenya. Cost

Effectiveness and Resource Allocation 2014 12:26.

\section{Submit your next manuscript to BioMed Central and take full advantage of:}

- Convenient online submission

- Thorough peer review

- No space constraints or color figure charges

- Immediate publication on acceptance

- Inclusion in PubMed, CAS, Scopus and Google Scholar

- Research which is freely available for redistribution 